\title{
ads!
}

\section{TVISA PARA LA}

THATEPIA TREDICA

\section{JHETCANA,}

\section{ARREGLADO POR UNA COMISION}

NOMBRADA POR LA ACADEMIA MEDICO-QUIRURGICA

\section{DE ESTA CAPITAL,}

\section{QUIEN HA DISPUESTO SE IMPRIMA}

POR CONSIDERARLO UTIL.

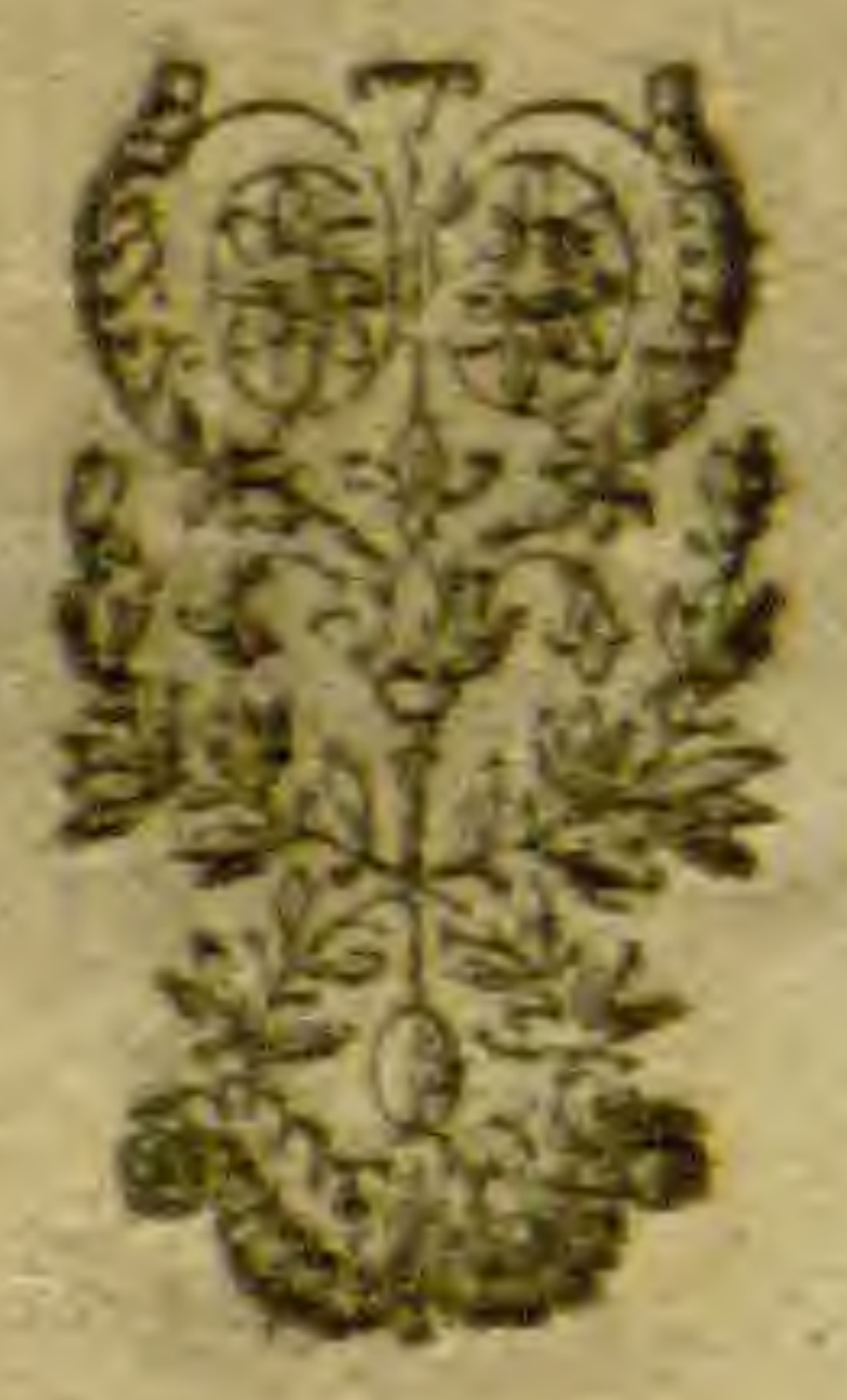

\section{एक \\ -}

Oficina del hospital de S. Pedro, à cargo del C. Manuel Buen-Abad. 


\section{III. \\ PRPLIDGA.}

(6)

Uonsiderando los perjuicios que pueden resultar á la humanidad de usar en la medicina cualesquiera producciones naturales, sin tener ántes conocimiento cientifico de ellas, se hace por lo mismo necesario trabajar con el mayor empeño, á fin de arreglar y reducir á sus nombres genéricos y específicos varias de aquellas, que siendo de bastante consumo en las boticas de nuestra República, solo se conocen por los vulgares, que sobre ser por lo comun insignificantes, tieneń ademas el doble inconveniente de conocerse bajo de un mismo nombre, sustancias muy diferentes, y no poderse recetar metodicamente por los profesores, cuando llega el caso de preseribirlas en sus recetas.

Para evitar, pues, estos notables defectos, é ilustrar, en la parte posible, la Materia Mlédica Mexicana, se ha dispuesto este pequeño ensayo, que podrá servir en parte para ella, comprendiendo en él las producciones de los tres reinos de la naturaleza que han podido reunirse, y que son de uso peculiar en esta República, habiendo adoptado el òrden de empezar por los nombres vulgares, poniendo á continuacion los genéricos con los específicos, en aquellas que se ha logrado averiguarlos; pues la dificultad de poder conseguir principalmente 


\section{IV.}

las plantas en estado de determinarse, ya por la distancia de los lugares en que se dan, ya por no ser facil hacer un viage para ir á reconocerlas, y ya, en fin, por la falta de correspondientes facultatiros, ha impedido llenar el deseo de presentarlas todas con sus propios nombres genéricos $y$-especificos.

Cuando se ha logrado saber cl autor ó autores que han tratado sobrg la sustancia de que se habla, se citan en seguida del nombre genérico y específico dando al mismo tiempo una noticia de los lugares en que nac̄en, y de sus usos y virtudes mas conocidas.

A fin de encontrar con mas facilidad cualquiera sustancia pedida por su nombre vulgar, se pone un indice por orden alfabético en que se manifiesta la mutua correspondencia de este con el nombre genèrico y especifico. En seguida se pone otro indice de los nombres genéricos y específicos con espresion de los vulgares que les corresponden. A continuacion de este indice sigue un catálogo, bajo el nombre de Suceduneos,que comprende varias plantas sustituidas ea nuestras boticas por otras tan diferentes de las verdaderas, contenidas en las Materics médicas estrangeras, que muchas de ellas no corresponden, ni en gènero, ni en rspecie, y otras que convienen solo en aquel, y no en esta.

Sin embargo de conocer lo imperfecto de este pequeño trabajo, ha parecido útil publicarlo, contando con que en la República no faltan profesores de Medicina, Farmacia, y otros 


\section{V.}

sabios en diferentes facultades, tambien dedicados á los ramos de historia natural, é interesados en sus progresos, que no solo podran corregirlo, sino llevarlo ademas al grado de perfeccion que se desea.

D. Vicente Cervantes, recomendable profesor de farmacia y Catedratico de botanica que fué mucho tiempo en Miéxico, arregló, para la Ifateria medica del pais, un discurso sobre las plantas medicinales que crecen en las cercanias de dicha Capital, el cual leyò en la apertura del curso de botanica el dia 23 de Mayo de 1791, y en él (que se ha tenido á la vista), presenta bastante número de aquellas, haciendo relacion de sus principales usos en la medicina, tanto de las conocidas en las Materias medicas, como de las que se usaban con particularidad en la Repùblica sin ser conocidas en ellas.

Siendo á proporcion de la estension y feracidad de este suelo, el nummero de preciosos vegetales con que nos brinda la naturaleza, seria par lo mismo mas facil reemplazar ventajosamente con los indigenos, aquellos que nos conducen los estrangeros, pues á reces llegan á nuestras manos evaporados por su mala repocision, y no pocas adulterados, euyos inconyenientes se evitarian colectandolos en el país; siendo facil de este modo reponerlos mejor, tenerlos mas frescos, y á precios mas coinodos.

Estas mismas ideas manifestò tambien el celebre profesor de medicina y botanico de 


\section{îi.}

fas espediciones facultativas de esta Republica D. José Mariano Mociño, en el discurso que pronunció en México, el dia 15 de Junio de 1801, para dar principio á las lecciones de botanica, inserto en las gacetas de la misma Capital de Septiembre del propio año, nùmeros 42 y 43, y estractado en los Anales de ciencias naturales, tomo 5.0 impreso en Madrid en el año de 1802, cuyo objeto fué manifestar en él la intutilidad de muchas medicinas que se gastan en las boticas, la impropiedad con que se sustituyen otras, y las que podrian usarse con provecho, segun las observaciones que tuyo proporcion de hacer, en union de otros sabios profesores de medieina, en las salas establecidas al intento en los hospitales de la Capital de México.

Para afirmar mejor su idea se esplica de este modo. "No hay droga alguna medicínal, esceptuando tres ò cuatro, de que no estemos surtidos abundantisimamente en nuestro suelo, que produce ó las mismas especies puntualmente, ú otras equivalentes de igaal, ô tal vez de mayar eticacia. No resta mas que el que quieran los facultativos usar de ellas con discernimiento, para que pueda México gloriarse de tener su materia medica propia, compuesta solo de los remedios de virtud indisputable."

En seguida hace una enumeracion de las sustancias que usaban en las referidas salas de observacion, y se omite el hablar aqui de 


\section{VII.}

ellas por no hacer mas larga esta introduccion; pero se copian al fin de los sucedaneos, por lo que pueda importar á los facultativos interesados en los progresos de una parte de la medicina $\tan$ necesaria como es la Materia medica.

El Dr. en medicina D. Luis Montan̄a, no menos recomendable que los anteriores, por su literatura y vastos conocimientos en la historia natural, hace ver en el discurso que pronunció para la apertura del curso de botanica en el jardin de México el dia 2 Junio de 1302 , inserto en el tomo $6 .^{\circ}$ de los citados Anales de ciencias naturales, impreso en Madrid el año de 1803, la necesidad que tienen los profesores de los ramos de medicina de adquirir conocimientos de la botanica para el mejor desempeño de ellos.

Parece, en fin, que el dictamen de tres sabios profesores que dejaron á la posteridad pruebas irrefragables de su instruccion y buena critica en varias ciencias, y con particular ridad en la historia natural, es bastante para recomendar la empresa de la Materia medica mexicana en beneficio de la humanidad doliente, y en honor de una nacion que tiene la dicha de disfrutar de un suelo tan abundante en producciones naturales, como en ingenios sobresalientes. 


\section{VIII.}

\section{c)}

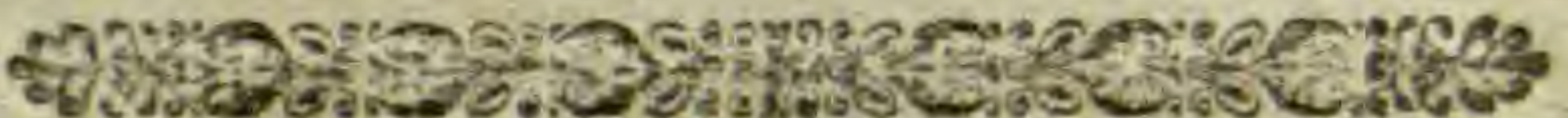

(2)

We ha citado el tomo y página de la obra del Dr. Hernandez, edicion de Madrid, cuando el vejetal ò sustancia de que se habla, pudiera confundirse con otra del mismo autor, que siendo diferente la da el mismo nombre. Cuando se habla de la edicion romana siempre se cita la página.

Sin embargo de considerar que la mayor parte de las plantas que se espresan de la Flora IIexicana Inedita, se hallarán ya publicadas por otros autores, y colocadas, unas, en distintós géneros, y otras, en especies diferentes, se ha tenido por conveniente el conservar los nombres de aquella, mientras no hay proporcion de examinarlas y cotejarlas.

Como varias de las sustancias contenidas en este ensayo, han sido mas bien conocidas y usadas por los indigenas y gente del campo, ò á lo mas observadas por algunos autores antiguos, que no por los facultativos modemos, nos hemos acomodado al lenguage que aquellos usaron al tratar del modo de aplicarlas y de sus virtudes, aunque consideramos imperfecto el primero, $y$ exageradas $y$ aun contradictorias las segundas; pero esto mismo podrá ser un motivo para que las respectables Academias y Juntas de la facultad reunida de medicina, en 


\section{IX.}

vista de estos incompletos trabajos, los vayan perfeccionando hasta poder formar una II $a$ teria médica mexicana; desechando lo que fuere inútil, y conservando lo útil; y marcando á cada sustancia las virtudes que verdaderamente taviese, segun la demostracion de repetidos espe. rimentos que deben preceder de ellas.

Es tambien indispensable analizar las aguas minerales de la República, tales son: las acidulas del Peñol y pocito de Guadalupe de México, las hidrosulfurosas de Puebla, las acidulas de Axocopam en Atlixco, la potable del Ojo de Alhuelica en Tehuacan, tan recomendada para deshacer el cálculo de la vegiga, los baños de agua muy caliente de Yztatlalan, los de vapor conocidos por los Humeros, de que hasta ahora tenemos noticia; pues averiguados los principios de que constan, se sabria á que enfermedades convendria aplicarlas; y á cuales no; $y$ en fin podrian prepararse por medio de la Sintesis, principalmente para los enfermos imposibilitados de caminar.

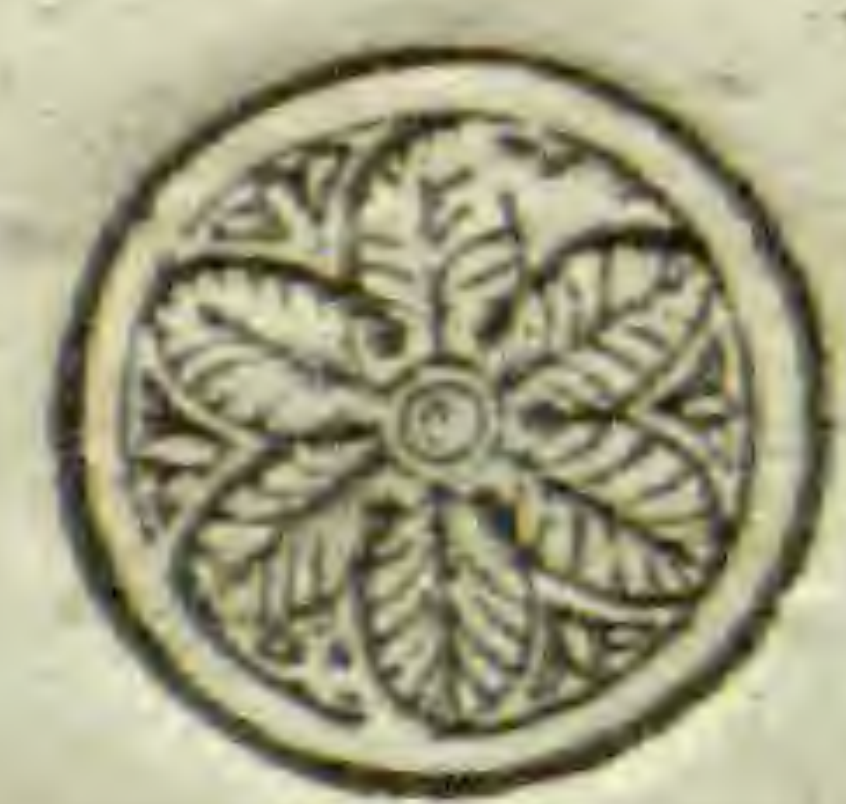




\section{NONBRES DE LOS AUTORES}

que se citan en abreviatura en este

$$
\begin{aligned}
& \text { Ensayo. }
\end{aligned}
$$

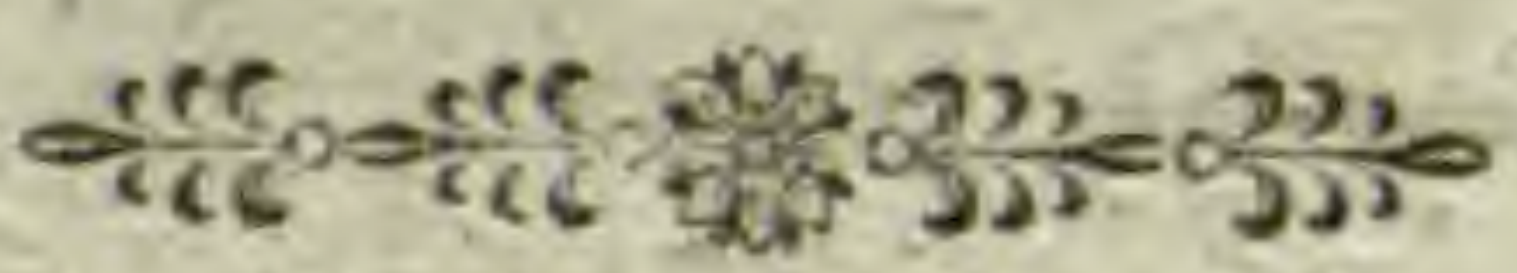

Ait........................ Aiton. Cav ................... Cavanilles. Cerv.................... Cervantes. Desv ................... A. Desvaux, Dun..................... Dunal. F. M. I . . . . . . . . Flora Mexicana Inedita. Hern................ El Dr. Hernandez. Jacq.................. Jacquin. Juss.....................Jussieu K. . . . . . . . . . . . L..................... Linneo. Lam..................... Lamarck. Lex ................... Lexarza. Llav................. EI Sr. Dr. Llave. Orteg...................... Ortega. Pal.......................... 


\section{XI.}

R. et. P................ Ruiz y Pavon Sims........................ Sims. Spreng...................... Sprengel. Sw........................ Swartz, W.......................Willdenow.

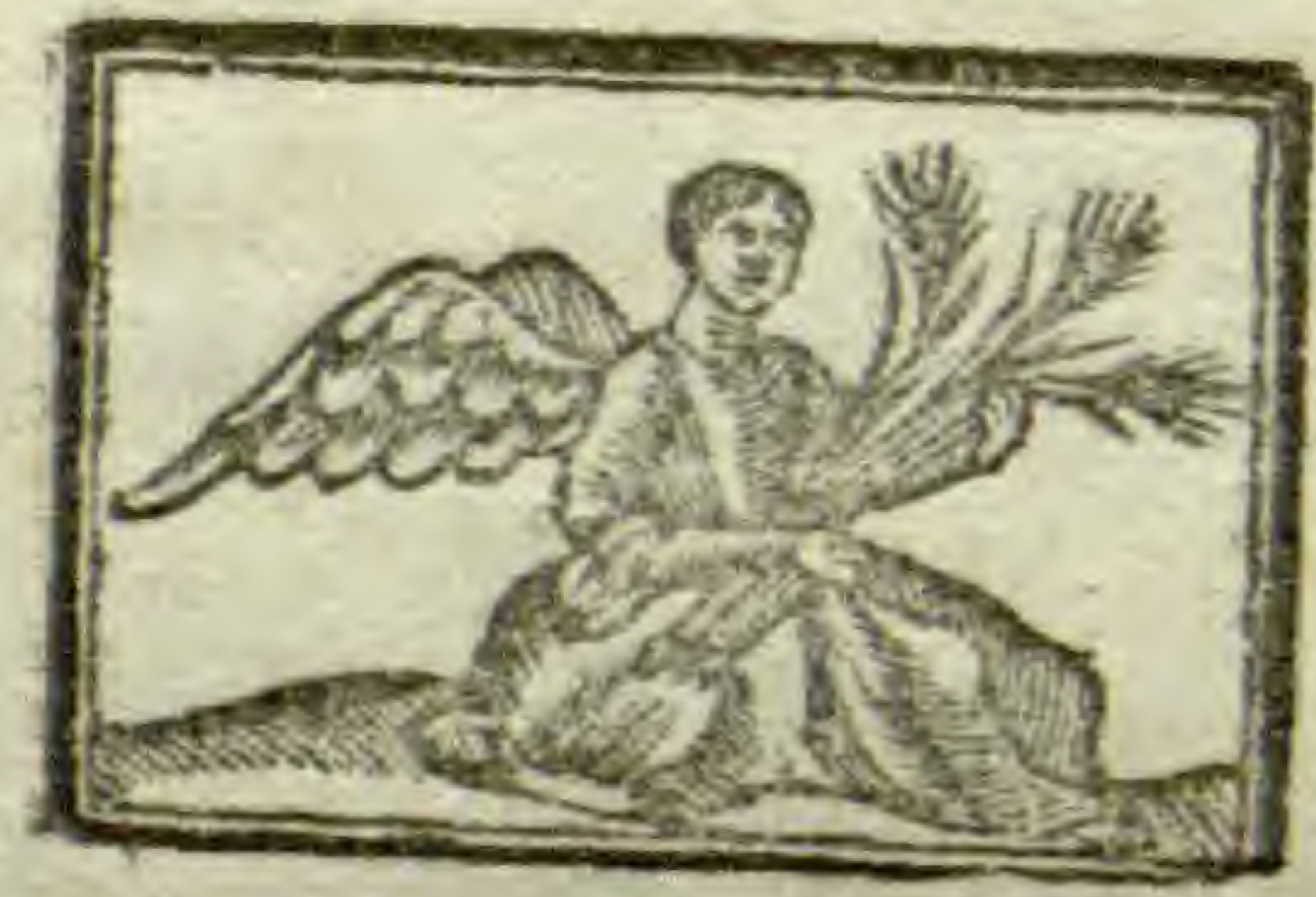




\section{PEINO VEGETAL.}

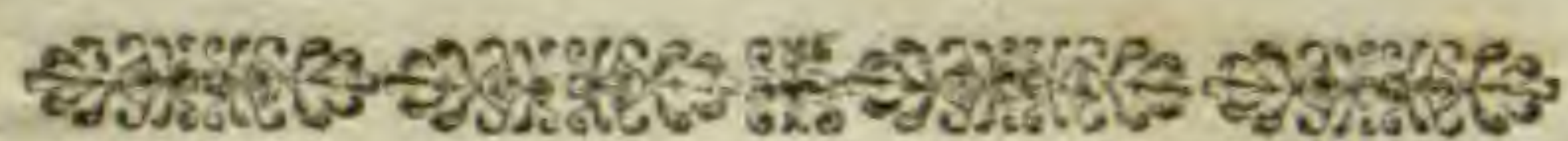

\section{Abelmosco ó Algalia. (Hibiscus Abelmoschus, L.)}

\section{M.}

LEL Asta planta se cuitiva en los jardines, y se halla bastante propagada en Cordova, segun informes de algunos de sus habitantes.

Estos aseguran que sus semillas producen efectos muy favorables en las mordeduras de las víboras ponzoñosas, muy comunes en aquellos contornos, tomando interiormente el cocimiento de ellas, lavando con él la parte mordida, y aplicando despues sobre ella las mismas semillas machacadas en forma de cataplasma.

Dichas semillas se reputan por antiespasmódicas tomándolas en emulsion ú orehata, en cantidad de dos dracmas por libra de agua.

\section{Alflerillo. (Geranium Cicutarium, L.)}

Es planta muy comun en los contornos de Puebla.

Su cocimiento, endulzado con miel rosada ó con otro jarabe apropiado, se usa en gárgaras, como detergente, en las afecciones inflamatorias de la garganta. 


\section{Alquitira del país. (Vease Tragacanto del pais.)}

\section{Aquequesqui. (Arum?)}

\section{Se produce en Atlixco.}

El habito de esta planta manifiesta ser de la familia de las Aroideas de Juss.; pero no han podido observarse sus flores, ni tampoco la fructificacion, $y$ sí las hojas, que son alabardadas, puntiagudas, $\mathrm{y}$ sus ángulos casi romos, con nervios muy realzados en el envés; los inferiores divididos en otros, y los superiores sencillos: sus intermedios venosos y blanquecinos. La longitud de ellas llega hasta dos tercias, y el ancho casi de media vara. Es acre, picante y caustica, cuyas propiedades se esplican con mas actividad en el pezon, que es plano por arriba, y forma dos ángulos á los lados, con la parte inferior convexa, esponjoso en lo interior, $y$ mas largo que la hoja.

Se hace mucho uso de estas hojas para resolver los edemas, aplicándolas sobre ellos calientes y rociadas con aguardiente: se mantienen puestas hasta que se sequen, y entonces se renuevan si hay necesidad; pero ennviene advertir que solo deben usarse en los edemas pasivos ó que están sostenidos por falta de accion de los sistemas linfatico y celular. 
En los edemas inflamatorios, aumentando la irritacion, aumentarian tambien la enfermedad.

\section{Arbol del Perú, ó falsa pimienta.} (Schinus Molle, L.)

Este árbol se hallá con freeuencia en las cercanias de Puebla y México.

El Dr. Hernandez espone que fué traida esta planta desde el Perú à éste país, y muchos lo creen asi fundándose en el mismo nombre que le dan algunos indigenas de Pelonquahuitl, esto es árbol del Perú; pero otros muchos le llaman Copalquahuitl, y al fruto Copalastle, de manera que la cosa se ha hecho problematiea: algunos (y nosotros con ellos) opinan que pueda ser produccion indigena por hallarse tan propagado este árbol en toda la república, donde està bastante atrasada la agricultura, y no ser mucho el tiempo que se supone de la introduceian de la misma planta en aquella. El fruto es estimado por cefalico, estomacal, diuretico y corroborante, cuyas cualidas se atribuyen tambien á la resina que fluye espontaneamente del troneo y ramas. El eocimiento de las hojas, hecho con una onza de ellas fresces para eada libra de agua, aprovecha en los edemas pasivos lavándose con él; mascadas afirman los dientes, y es útil en las ulceras atónicas de la boca. 


\section{Archipin. (Burscria(?)gummifera,. Jacq.)}

Aunque este autor describe completamente este árbol en su obra Selectarum stirpium Americanarum Historia, pag. 94 à 96, y lo presenta dibujado, tabla L.XV., no se ha proporcionado examinar si es el mismo que produce el Archipin, por cuyo motivo se pone en duda, inclinándonos á creer que pueda serlo por las relaciones recibidas de algunos botánicos. Asegura que todo el árbol contiene un zumo acuoso, glutinoso, balsámico, abundante, de un olor parecido al de la trementina, sin ser desagradable, $y$ que se espesa à manera de goma cuando sale à la superficie y le da el aire. Nada dice acerca de los usos de esta sustancia.

La que conocemos con el nombre de $A \hat{r}$ chipin, nos viene en pedazos de distintas figuras y tamaños, de diversos colores: unos, se hallan de un blanco que tira á amarillo interior $\mathrm{y}$ esteriormente, y partidos presentan el aspecto de la cera: otros, pardos en lo esterior, y en lo interior de color de cera amarilla, con vetas que tiran á negro por fuera y dentro, cuya fractura es vidriosa, y se asemeja á la goma amoniaco. Su olor, parecido al del incienso, y arde como éste aplicado á la Hlama.

Habiendo puesto una dracma de esta sustancia en polvo con una onza de alcohol de 
$800^{\circ}$ se disolvió en frio casi toda: por otra parte se mezcló otra dracma de dicha sustancia pulverizada con una onza de agua destilada, y quedó en suspensión en ella en consistencia y aspecto de emulsion, que agitándola en un frasquito formaba mucha espuma, y permaneciendo en quietud no se separaba del agua, $y$ sí al cabo de algunos dias, pero con mucha lentitud, conservando su color blanco la materia resinosa, y el líquido de encima turbio, de color amarillo rojizo; por cuyos resultados parece ser una sustancia resinogomosa.

Se hace uso de ella por algunos facultativos, en dosis de medio escrupulo à media dracma, en un cocimiento aperitivo para las hidropesias:

Teniendo al parecer tanta semejanza po su olor al disolverse en agua, y por su sabor amargo con la gama amoniaco, podria emplearse en las preparaciones farmaceuticas en que entra esta.

Jacquin hallò este árbol en Cuba, Santo Domingo y Jamaica. Eñ la república mexicana, existe el que produce el Archipin.

\section{Atlanchan. (Cuphea Lanceolata, $k$.)}

Se cria con abundancia en los alrededores. de Puebla.

En esta ciudad la usan las comadres como un poderoso corroborante de las paridas, un- 
tándolas las espaldas y caderas con la yerva fresca, bien muchacada, despues de haberse bañado en el Temazcalli, (1). Cuando no se logra fresea la yerba hacen una tintura alcoholica con la seca, la que usan en friegas en las mismas partes que aplican aquella, y segun dicen con iguales efectos.

\section{Barbudilla.}

(Dorstenia Contrayerba, L.-Tuzpatli, Hern.)

Se cria en tierras calientes.

Su raiz es la legitima Contrayerba que se gasta en las oficinas de Europa. Tiene un olor aromatico y un sabor acre, caliente, algo amargo y persistente. Su virtud es estimulante, tonica y diaforetica, y se recomienda en las fiebres pútridas ò adinamicas.

En la república se gasta, con el nombre de Contrayerba, la que viene de Julimes ( $\boldsymbol{A}$ sclepias contrayerba, $\boldsymbol{F}, \boldsymbol{M}, \boldsymbol{I}$.), y se cria tambien en los montes pròximos à Guanajuato. Es muy distinta de la Barbudilla, aunque igual ò superior en los efectos, segun las observaciones de casi todos los mèdicos mexicanos.

\section{Begonia, (Begonia Balmisiana, F. M. I.)}

Nace en Patzcuaro y Ocuila,

(1) Temazcalli, es un horno que sirve parat recibir una espeeie de baños de vapor, cuyo origen viene desde los antiguos mexicanos, 
Esta planta fué dedicada á D. Francisco Javier Balmis por los botànicos de las espediciones facultativas de esta república, en razon de haber sido el primero que la trasportó y diò à conocer en Europa, y el que trabajó con mas esmero en perfeccionar su uso medicinal.

El mismo Balmis, tratando de sus virtudes, dice: „La raiz tiene un sabor amargo fastidioso, y su cualidad es purgante drastico, dada en gran cantidad; pero en dosis proporcionadas, purga con suavidad:.:: promueve la menstruacion (cuando esta se detiene por falta de accion en el útero), y en su virtud fundente y antivenerea se asemeja al Agave, con sola la diferencia de que esta ùltima obra principalmente excitando la orina y promoviendo el sudor, y aquella purgando los intestinos, „Usase comunmente esta raiz en forma de enema, despues de reducida á polvos sutili, simos, y en cantidad de treinta á cuarenta granos para los sugetos robustos, mezclándose en media libra del cocimiento emoliente; pero estas dosis deberán aumentarse ò disminuirse á proporcion de la robustez del enfermo y de su facilidad en irritarse. Puede tambien darse por la boca; pero ha de ser en menor cantidad, bastando de diez y ocho á veinte granos para una vez, desleidos en una ó dos onzas de agua comun, bebiendo encima un yaso de la misma". 


\section{8}

"Sucede algunas reces que el sabor ingrato y amargo de estos polvos provoca á nausea, estimulo que conviene promover hasta excitar el vòmito en los enfermos que tienen sobrecargadas las primeras vias, y con señales de saburra; pero en el caso que convenga evitar dicho vơmito, se harán de ellos pildoras con la miga de pan. Tambien se dan en infusion á las personas débiles y delicadas, infundiendo en suficiente cantidad de agua la misma dosis de polvos" (1).

\section{Cabezuela. (Centaurea Cyanus, $L$.)}

Se sabe que se eultivaba en Juchimilco y se vendia en la plaza de México con el nombre de botoncillo.

A esta planta atribuyeron los antiguos varias virtndes, $y$ entre ellas la de ser un poderoso diuretico; pero en el dia solo se emplea en las optalmias ligeras. (Alibert: Nowveaux etemens de Therapentique et de Matière medicale. Cinquieme edition.)

\section{Cacahuate.}

(Arachis Hipogaea, L.)

Se cosecha con abundancia en tierras

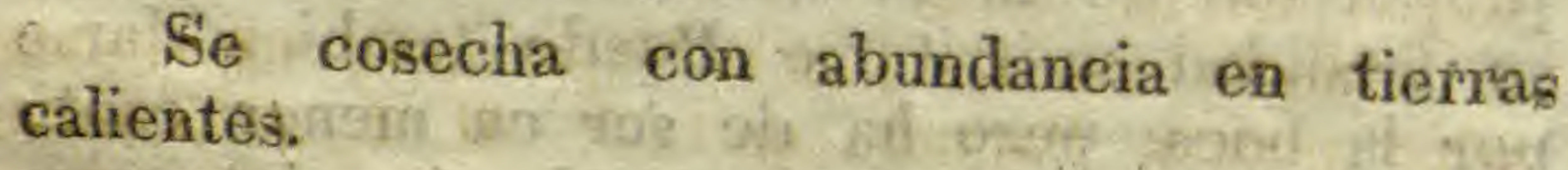

(1) Balmis: Demostracion de las eficaces virtudes nuevamente descrbiertas en las raices de dos plantas, especies de Agave y Begonia \&c. Impresa en Madrid año de 1794, pag. 341,343 y 344. 
Dice el Dr. Hernandez que esta planta no era conocida antiguamente en estos paises, sino propia de las Islas, adonde llaman el fruto Mani. Comido este con abundancia irrita el aparato digestivo, y desarrolla simpatias del mismo genero en otros aparatos, principalmente en el genito urinario y el encéfalo; pero su aceite por espresion, recientemente sacado, es anodino y calmante, conviniendo en mucho con el aceite de almendras dulces. Capitaneja. (Platypteris Crocata, K.-Bidens Crosata, Cav.-
Spilanthus Crocatus, Sims.)

Nace en Atlixco, Matamoros y los montes de Cordova.

El principal uso de esta planta es lavar con su cocimiento, preparado con media onza de la yerba seca para una libra de agua, las llagas venereas, echando despues sobre ellas el polvo de la propia yerba, El mismo cocimiento, agregándole la yerba del pollo ( $\boldsymbol{T} r a$ descantia erecta, Cav.), á partes iguales de cada una, se usa tambien como enjuagatorio para las llagas de la boca.

Suele usarse por la Capitaneja espresada, otra planta, llamada en la F. M. I. Helianthus alatus, y por Cav. posteriormente Coreopsis alata, cuyas virtudes convienen con ella, segun las observaciones de los facultatiros. 


\section{Capuchina. (Fease Mastuerzo de Indias.)}

Cebolleja. (Veratrum Sabadilla, Pal. Practica de Botanica de $L$.)

Es la raiz de la planta conocida con el nombre de Cebadilla, que nace en climas calientes.

Es acre y estornutatoria como la semilla, y es uno de los simptes que entran en la composicion de los polvos de Sandoval, citados en el Chapìz.

La semilla, segun Meissner, Pelletier y Caventou, contiene, acido cebadico y veratrina ó sabadillina. Es escitante é irritante, que usado interiormente produce dolores de estomago y yòmitos: $y$ al esterior la inflamacion de la piel, con especialidad en los sugetos jovenes. Se emplea para matar los piojos y las lombrices intestinales. Seeliger la ha usado con buen exito contra la tenia; pero es menester para usarla de mucha circunspeccion. (Farmacopea universal por A.J. L. Jourdan). Vease tambien-Alibert: Nouveaux elemens de Therapeutique et Matière medicale. Cinquieme edition.

\section{Cihoapatli ó Zoapatle. (Eriosoma Floribunda, K.-Montativa Tomentosa, Cerv.) (1).}

Crece en los alrededores de Puebla, y par-

(1) Cerv. se la dedicó al Dr. D. Luis Montaña, natural de Puebla, insigne médico y naturalista, como se manifiesta en el Fasciculus Se. 
ticularmente en el cerro y barranca de Guadalupe.

Toda la planta es estomática, diurética y pectoral.

El Dr. Hernandez la recomienda en el tomo 2,0 página 136 , para las mugeres que estan de parto, diciendo que dos ó tres onzas de su zumo, ò de su cocimiento, surten en estas ocasiones felicisimos efectos, los cuales ha confirmado la continua esperiencia que se tiene de dicha planta, haciendo de ella los mismos usos en el dia; pero debe advertirse que solo debe usarse en los partos perezosos, cuando estos no dependen de una mala posicion de la criatura.

\section{Ciruelo del país. (Spondias Myrobalanus, L.)}

Es árbol que se da en tierra caliente. Su fruto, llamado ciruela, es bien conocido por el uso general que se hace de él en las mesas, como fruta inocente y sabrosa, teniendola por fresca en razon del acido que contiene su pulpa. Si se come en mucha cantidad, es purgante, haciendo despues el efecto de estreñir como los mirobalanos (Terminalia. L.). conocidos en la medicina.

cundus ex Llave et Lexarza. 


\section{Copal blanco. (Heliocarpus Copalifera, F. M. I.)}

Esta resina nos viene por el mes de noviembre de tierra caliente, en figura de pencas, de color muy blanco, olor aromàtico molesto, de la cual se sirven los indigenas para perfumes en el dia de difuntos. Con el discurso del tiempo su color blanco se pone amarillo, y su olor entonces es menos activo.

Se usa ya en polvo, ya en cocimiento para la curacion de las heridas y ulceras atonicas, y aplicada en forma de parches á las sienes, mitiga las cefalalgias. Se le dan otros muchos usos en la farmacia, como puede verse en los Sucedaneos, hablando de la goma de limon.

Cuajilote.

(Crescentia Musaecarpa, F.M. I.-Crescentia EduSe da en tierra caliente.

El cocimiento de su raiz, hecho con media onza para una libra de agua comun, $\mathrm{y}$ bebido á pasto, se usa frecuentemente en las hidropesias. El cocimiento de las hojas, instilado en los oidos, aprovecha en la otitis aguda. Con la pulpa contenida en el fruto se prepara un jarabe que se usa como temperante. El fruto es tambien comestible.

Cuauchalalá.

(.Aun no se ha podido reconoeer su genero.)

Sus cortezas se nos traen de Matamoros y sus cercanias. 
Algunas de ellas son enteramente arrolladas, y otras acanaladas, de color rojizo por la parte interior, y por el esterior pardo con manchas cenicientas; olor, semejante ál de la corteza de encino, aunque mas agradable; sabor, astringente con algun amargo.

El cocimiento de estas cortezas se usa para afirmar la dentadura, cuando está floja; y los albeitares aplican su polvo á las llagas de las béstias,

\section{Cuautecomate ò tecomate, Güiro.}

(Crescentia Alata, K-Crescentia Ternata, F.M. I.-Quauhtecomath, Hérn.)

Se nos trae de tierra caliente.

Con la pulpa de este fruto se hacen en las boticas un jarabe $y$ una conserva, $y$ ambas cosas se recomiendan como pectorales; $y$ el cocimiento de la misma se usa en las contusiones $\mathrm{y}$ ulceras internas.

\section{Chapúz ó yerba de làs ànimas.} (Helenium Autumaale, L.)

Se da con bastante abundancia en los contornos de Puebla, y con especialidad por ChoIula y Totomehuacan.

Toda la planta es errina ó estornutatoria, y particularmente sus flores y semillas, que estregadas entre los dedos, é introducidas en las narices, causan repetidos estornudos, Es uno de 


\section{4}

los simples que entran, (particutarmente en Puebla), en los polvos estornutarios, conocidos en nuestras boticas con el nombre de Sandoval.

Por la analogia que tiene con la Arnica montana, se ha sustituido su estracto por el de esta, cuando se ha escaseado, de conformidad con los profesores, quienes aseguran haber conseguido efectos muy semejantes.

\section{Chia. (Salvia Hispanica, L?}

Se cria con abundancia en tierra caliente, y podria darse muy bien en temperamentos templados.

La semilla es mucilaginosa, anodina, pectoral, demulcente, laxante, y puede suplir muy bien por la Zaragatona, y aun acaso con ventajas. Es bien conocido el uso que hacen del agua de chia para refrescar en la estacion calurosa,

\section{Chicalote. (Argemone Mexicana, L.)}

Es muy comun en toda la República. Esta yerba da por incision un zumo amarillo, que se recoge vulgarmente por medio de hilas ò algodones: despues se disuelve este zumo en agua comun, y la usan por lo general, echándola dentro de los ojos, para consumir las nubes incipientes, $\mathrm{y}$ destruir las manchas $\mathrm{y}$ carnosidades que suelen salir en ellos, 
Chicozapote. (Acluas. Sapota, E., Jacq. Am. 5\%. 1. 41.)

Se produce en los paises calientes.

Sus semillas descortezadas son diuréticas: se usan en las disurias, estangurrias y enfermedades semejantes, administrándolas en emulsiones (echando seis semillas para cada dosis), y se continuan por algunos dias hasta conseguir alivio; pero sin pasar jamás del número de doce, porque á mas de creerse que son eméticas en alta dosis, causan crueles dolores, y se esponen á peligrar los que las tomen. La corteza del tronco, dice el célebre Jacquin, que la tomaban algunos en las Islas con feliz suceso, en lugar de la quina, para cortar las tercianas.

\section{Damiana. (Cineraria Mexicana, F. M. I.)}

Se cria en los alrededores de México. El Dr. Montaña la usaba en baños; pero aun no sabemos con certeza si Jos aplicaba para los dolores reumáticos.

\section{Epasote ó epazotl. (Chenopodiun Ambrosioides, L.)}

Es comun en toda la Repüblica, y bien conocido por el uso que se hace de él en varios alimentos.

Usada su infusion como medicina, escita poderosamente el sudor, la orina y la menstrua- 
cion, cuando está detenida por atonia del útero; cura los flatos y corrobora el estònago. Se ha usado como escitante en los catarros crónicos (Farmacopea universal citada).

Podria usarse en lugar del té de China, y acaso con mayores ventajas.

En Europa se conoce tambien esta planta con el nombre de té de México.

\section{Epazotl. (Vease Epqsote.)}

\section{Espinosilla. (Hoitzia Coccinea, Cav.)}

Nace con abundancia en los contornos de Puebla.

Es un poderoso sudorifico, $y$ cuando no mueve el sudor, obra como un buen diurético.

\section{Falsa pimienta. (Vease àrbol del Perú.)}

\section{Flor de encino, de México.(Tillandsio Lingulata, F. M. I.)}

Esta planta parasitica, que nace y florece sobre los encinos, y por tanto la llaman impropiamente como queda referido, se encuentra con otras varias especies en los montes de $\mathrm{S}$. Angel y Tlalpan.

Se usan indistintamente las hojas, tallos y flores de diferentes especies del mismo género, como astringentes y pectorales. 
En algunas de estas plantas se recoge en tiempo de lluvias mucha porcion de agua por tener la hojas en su base una cavidad suficiente para contenerla, la cuat conservan sin corrupcion por mncho tiempo, sirviendo de refrigerio à los pastores, carboneros y caminantes.

\section{Flor de encino, de Puebla. (Quercus, $L$ )}

Son los amentos de las flores masculinas de las varias especies de dicho género, que se crian en los montes cercanos de Puebla.

Las atribuyen las mismas virtudes que á las flores de tilo, y por lo mismo se consideran como anodinas, antiespasmodticas, y se usan en los vertigos y epilepsia.

\section{Flor de pascua. (Euphorbia Heterophylla, $L_{4}$ )}

Se da mucha en Atlixco y Orizava.

Cuando las nodrizas advierten escasez de leche, toman para aumentarla, segun se persuaden, una infusion de esta flor, echando dos dracmas en un cuartillo de agua comun, que sirve para dos ocasiones al dia, y endulzándola con jarabe de adormideras ò azucar: tambien mezclan la misma infusion con pulque (1), ò bien hierben en este solo la flor. Entra esta en los polvos que comunmente llaman para apoyar, cuya formula es conocida en nuestras boticas,

(1) Vease Magruey. 


\section{Goma de Sonora. (Laccae Species?)}

Los caractéres que à primera vista presenta esta sustancia resinosa, denotan ser alguna especie de laca, y acaso elaborada por el mismo insecto (Cocus lacca), ó por otros perténecientes al mismo género.

Nos viene esta sustancia del Estado que la da el nombre, unas veces en pedazos irre. gulares, como los de la laca, de un rojo oscuro hasta llegar á pardo, faciles de romperse con los dedos; y otras en cilinadros del peso de dos ó mas libras, con una superficie desigual, y vetas de los colores indicados; pero que sobresale mas el rojo: en lo interior se presentan los mismos, aunque mas confundidos; su olor es suave, y se inclina algun tanto al de la cera amarilla; su sabor acidulo-salado. Se rompe entre los dientes haciendo ruido, y bien masticada tiñe la saliva de color morado, se ablanda y pega á los dientes á manera de resina. Se considera como un astringente suave, y se aplica en polvo, en dosis de un escrùpulo á media dracma, diluida en vino ó agua comun, cada tres horas para los flujos pasivos uterinos. Algunos la han considerado como antiespasmodica; pero esto deberà acreditarse con viteriores esperimentos. La gastan tambien, como la laca, para barnices. 


\section{Güiro. (Vease Cuautecomate.)}

\section{Ilaba de Indias. (Iura Crepitans, L.)}

Se cria en Chilpancingo (Brabos), y en otras tierras análogas.

Hernandez atribuye á la almendra del fruto de esta planta la virtud vomitiva y purgante; pero la niega Sloan, diciendo haberla comido muchas veces sin esperimentar vòmito, ni pur. gacion alguna. (Palaue Practiea de botánica de Linneo, tom. 7, pag. 271). Si es la misma que se conoce con el nombre de Haba de Goatemala, podrá asegurarse que produce los mismos efectos que dice Hernandez.

Ultimamente se nos ha comunieado por un individuo observador y curioso, que quitando á esta semilla una membrana contenida en su interior, pierde la virtud vomitiva, quedándole solamente la purgante; pero aun nosotros no tenemos esta observacion. Para separarla se descorteza y desunen circularmente dos cuerpos carnosos (Cotiledones) que la cubren; y aunque por su consistencia se la ha dado el nombre de membrana, nosotros la tenemos por un verdadero embrion, plano $\mathrm{y}$ de la consistencia membiranosa, que se separa en dos. Fsta idea está en un todo conforme con lo que dice Car. en sus elementos de botànica, pag. CI. "No todas las partes del meollo tienen las mismas 
propiedades, lo que no debe llamar menos la atencion de los botánicos, que la de los médicos. La semilla entera de la lechetrezna, (Euphorbia de L.), purga con violencia, y esta virtud solamente reside en el embrion, $y$ no en la clara endurecida, que es dulce é inocente. Asimismo la virtud purgativa de la Jatropha Curcas, de L., solamente existe en su embrion, quitado el cual, la comen impunemente y con placer los negros del Senegal, segun dijo Adanson" Lo mismo asegura Bergio en su materia médica, pag. 824.

Hipecacuana del pais. (Solea Verticillata, Spreng.Viola Verticillata, Orteg.)

Con este último nombre la conocieron tambien los botánicos de las espediciones facultativas de esta República, y el catedrático de botánica de México D. Vicente Cervantes, leyò un discurso sobre ella y sus virtudes, en la apertura al curso de botánica el dia 3 de Junio de 1798 , cuyo estracto se halla inserto en los Anales de ciencias naturates, impreso en Madrid en 1803, pag. 185.

México.

Crece con abundancia en los contornos de

Segun se esplica el mismo Cervantes, fun. dandose en algunas esperiencias practicadas con su raiz, podrá suplir muy bien por la hipecacuana que nos viene del Brasil (Viola Ipecacuanha, $\boldsymbol{L}$, y las demás especies que se usan
en la medicina. 
Seria ventajoso para la humanidad é intereses de nuestra República, que los profesores de medicina se ocupasen en repetir los esperimentos con esta raix, porque resultando iguales en virtud, ya sea aumentando ó disminuyendo la dosis, deberia preferirse á las exòticas; de cuya medida resultaria no solo el ahorro de las cantidades que se invierten en su compra, sino que tal vez podria hacerse un ramo de comereio con la nuestra.

Jaltomate. (Saracha Dentata, R. et P. Flar. Perur, et Chilens. Prodromus pay. 31. t. 34.-Atropa Dentata, Spreng.)

Se cria en los contornos de Puebla, y su fruto (baya) cuando está maduro, toma el eolor y casi el tamaño del fruto del Capulin (Prunus Capuli, $(a v$.), en cuyo estado to comen las gen- tes sin esperimentar novedad alguna,

- Sus hojas cocidas en manteca de puerco, y. machacadas hasta la forma de cataplasma, se aplican para ablandar los tumores y mitigar los dolores. (Flor. peruv. et Chilens. tom. 2. pag. 43.)

Sería muy importante hacer algunas observaciones con esta planta por el bien que de ellas podria resultar á la humanidad; y no serian menos interesantes practicarlas con su raiz, pues correspondiendo eomo corresponde, á la misma familia de las Solanaceas, que la Mandragera (Atropa MIandragora, L.), acaso sus efectos serian análogos ó iguales. 
Con los polros de la raiz de la Mandra. gora cocidos en la cantidad sufieiente de agua, se hace una cataplasma que se usa como discuciente, (Frarmacopea hiniversal citada).-De este mismo modo podria aplicarse la de la Saracha, â fin de observar sus virtudes-

Jojobas. (Aùn no se conoce su gènero)

Estos frutos é semillas, segun notıcias, nos vienen de California.

Son oblongos, angúlosos, compuestos por defuera de una membrana ò cascarilla delgada, de color pardo oscuro semejante al de la castaña, su tamaño, poco mas ó menos, como el grano de un cacahuate (Arachis Hipogaea, L.), é interiormente de una sustancia carnosa, blanca, de sabor amargo.

Comiendo uno ó dos de estos frutos ò semillas cada tres horas, y repitiendose por algunos dias, aseguran que modera el ardor de la orina. Algunos las tienen tambien por antiacidas y emenagogas.

\section{Junquillo ó yerba de la alferecia, (Cacius Flageliformis, L.)}

Se cultiva con esmero en muchas casas, con el fin de dar la infusion de sus flores á las criaturas para preservarlas ò curarlas de la alferecia, cuando estan acometidas de ella, por creerse que goza de esta virtud. 


\section{Tignoaloe ó Linanué. (Amyriss)}

Se produce con abundancia en Ia Misteca y rumbo de Matamoros.

Por las noticias que han podido adquirirse de esta planta, y algunas semillas que se recibieron, hay mucha probabilidad que pertenezca al género referido.

Su- leño es ligero, de un color amarillo, con vetas en lo interior mas ó menos subidas de este mismo color, de un olor muy aromatico, especialmente cuando se escofina ò reduce á astillas, semejante al del leño rodino, por el cual suele sustituirse en las boticas. Su aceite volatil es de un olor bastante agradable, y por lo mismo se gasta para perfúmes.

\section{Linanué. (Vease Lignoaloe.)}

\section{Maguey. (Agave Americana, L.)}

Es generalmente conocido en esta República por las muchas utilidades que se sacan del zumo (agua miel), que despues de beneficiado se llama púlque. Este licor, que se usa como bebida regional, es celebrado por un poderoso diuretico, sudorifico, estomacal, digestivo, astringente, corroborante $y$ antiescorbutico.-El bálsamo de maguey que se prepara en las boticas, segun la formula conocida en 


\section{4}

ellas, es un escelente vulnerario. Con el zumo de las pencas asadas del maguey, mezelado con la suficiente cantidad de azucar, se forma un jarabe que se tiene por vulnerario y pectoral.

La goma que fluye espontamente de las hojas, de la que hablô en sus gacetas de literatura el Padre D. José Alzate, es identica con la goma arabiga, y puede sustituirse, sin riesgo alguno, en todos los casos en que se administra esta.

Los antiguos mexicanos hacian muchos usos de este precioso vegetal.

Posteriormente se le atribuyò á su raiz la virtud diaforetica $\mathrm{y}$ diuretica de que diò noticia el mexicano D. Nicolas Viana, y un gran número de observaciones han decidido ser dicha raiz un singular especifico para la lue venerea. En el vicio eserofuloso produce tambien muy favorables efectos. (1).

\section{Malagueta. (Vease Pimienta de Tabasco.)}

\section{Malva de Veracruz. (Sida Capensis, Cav.)}

Se cria con abundancia en las cercanias de aquel puerto, y en otras muchas partes de la República.

Se gasta á veces en Veracruz por la legítima malva (Malva rotundifolia, L.), por no

(1) Balmis: en su obra citada, pag. 302 y 303. 
producirse esta en aquel punto, y cuyas virtudes, como las demás especies de Sida, son análogas á las de la malva.

Mamey. (Lucuma Mammosa, Juss.-Achras Mammosa, L.)

Es árbol de tierra caliente, y cuyo fruto es bien conocido por el uso comun que tiene entre las frutas comestibles.

Entre los antiguos mexicanos era mas significativo su nombre, pues le llamaban Tezontzapotl, que quiere decir Zapote atenzontlado ò con color de Tezontle (1).

La corteza ò cáscara de la almendra, dice el Dr. Hernandez, que cura los afectos del corazon (la epilepsia), y bebida con vino, aprovecha en el cálculo y en el dolor de riñones, De la semilla descortezada se saca un aceite, conocido en estas oficinas de farmacia con el nombre de Pixile, parecido en su olor al de las almendras amargas, aunque de consistencia por lo regular espesa, y se usa como desobstruente untandolo en el vientre.

\section{Mlangle. (Rhyzophora Mangle, L)}

Crece en las cercanias de Acapulco y en otros puntos de la República.

(1) Almendrilla porosa de los mineralogistas y corresponde á la familia de Trap, ó Basalto. 4 


\section{6}

Su sustancia gomosa está formada en lágrimas de la longitud de una ò mas pulgadas, unas veces sencillas y estriadas, y otras compuestas de muchas làgrimas recargadas formando grupos: de aspecto vidrioso y trasparentes, que se rompen facilmente; color, cetrino que à veces tira á rojo; olor, que parece al de levadura, y sabor un poco acido; se disuelve lentamente en la boca formando mucilago sin romperse el grano: los pedazos tienen por un lado las cortezas que los unian al árbol.

Es anodina, atemperante y pectoral, y sus efectos son semejantes á los de la goma arabiga, ya sea en forma de jarabe, ò ya poniéndose en la boca un pedazo para disolverla poco á poco y tragarse la disolucion.

\section{Maravilla. (Mirabilis Jalappa, L.)}

Fs muy comun en la República.

Su raiz es purgante tomada en cantidad de dos dracmas, pulverizada, y en vehiculo proporcionado.

El célebre Padre Plumier, y Lignon informaron en Europa, déspues de haber viajado por la América, que la Jalapa de las oficinas, tan conocida en el comercio, se recogia de esta planta; pero son vegetales muy distintos, y aunque convengan en la virtud purgante, es mucho mas débil el de la Maravilla, que el de la Jalapa (Convolvulus Jalappa, L.) 


\section{7}

En las boticas se usa un unguento, preparado con la raiz de la Maravilla y manteca, para refrescar el pulmon.

\section{Mastuerzo de indias, ó Capuchina. (Tropaeolum Majus, L.)}

Se cultiva en las huertas y jardines.

Es acre, diurética y antiescorbutica, pudiendo suplir para llenar la última indicacion, por los berros, becabunga y cocleäria.

\section{Mercadela. (Calendula Officinalis, L.)}

- Creee en muchos huertos y jardines.

Se tiene por emenagoga y sudorifica, y se usa en las optalmias, vertigos y calenturas exantemáticas, aunque algunos autores dudan algo de estas virtudes,

\section{Mezquite ó Mizquitl. (Inga Circinalis, W:-Mino- sa Circinalis, $L$.)}

Es muy frecuente en la República, como lo son tambien otras varias especies de Ingas y Mimosas.

El Mezquite es una especie de la Acacia de los antiguos, de la que fluye una concrecion semejante á la legitima goma aràbiga oficinal (Mimosa Nilotica, L), y se usa por ella, tanto en la medieiná, como en las artes.-Igual- 


\section{8}

mente se prepara con el zumo de las hojas, ò bien con su cocimiento, un bálsamo bien conocido en las boticas, y de uso frecuente por los facultativos, para las optalmias crónicas: tambien se usa con el mismo fin el estracto de las propias hojas en consistencia baja.

\section{Milenrama. (Vease Plumagillo.)}

\section{Milizquitl. (Vease Mezquite.)}

\section{Mohuitli. (Vease Moictle.)}

\section{Moictle ó Mohuitli de Hern, Trompe. tilla. (Justicia Tinctoria $F, M, I$.}

Se produce en varios terrenos de la Re. pública, y se cultiva en varıos jardines.

Hernandez la recomienda en las disenterias, en el flujo inmoderado de la menstruacion, y en la sarna.

El Padre D. José Alzate publicó en las gacetas de literatura, la virtud antiapoplética de esta planta, y en el dia la usan generalmente como antiepiléptica.

Monacillo. (Paronia Veneta, Spreng.-Hibiscus Pentacarpos, L.)

Es muy comun en los huertos y jardines, en donde lo cultivan por la hermosura $y$ abun- 


\section{9}

dancia de sus flores, $y$ se da espontaneamente en los montes de Còrdova.

Sus virtudes convienen con las de las plantas columniferas, como son las malvas, sidas, hibiscos \&c.-En el dia se usa la infusion de sus flores, para corregir las inflamaciones del aparáto digestivo.

\section{Nananchi. (Vease Nanchi.)}

Nanchi ò Nananchi. (Malpighia Faginea, We)

Es comun en los paises calientes, $y$ con particularidad se nos trae de Matamoros y sus cercanias. Abunda tambien con otras varias especies, en el término de Córdova, y en particular en las sabánas.

El cocimiento de las cortezas, que son astringentes, sirve para afirmar la dentadura, como las del Cuauchaialá, y por lo regular suelen hembirse juntas. Se recomienda tambien como vulnerario.

\section{Nopalillo. (Caetus.Antidisenterieus, F. M. I.)}

Su raiz nos viene en pedazos mas ò menos circulares, del diámetro de una ò dos pulgadas, y grueso de 4 á 6 lineas, compacta, de color blanco con manchas pardas por lo interior, y en el esterior con una corteza que tira á gris, arrugada; olor, ninguno; sabor que 
se parece al del trigo, y bien mascada se ad vierte bastante mucilaginosa.

Es de algun uso en las boticas para las diarreas y disenterias. Administrada en polvo, en dosis de un escrúpulo á media dracma, cada tres horas, en un pocillo del cocimiento de la misma raiz, aprovecha para contener los: flujos de sangre uterinos, y las hemorragias del pulmon.

Palancapatli, de México. (Solidago Montana, F. M. I.)

Abunda en los montes del antiguo desier. to de PP. Carmelitas, y lo venden en la plaza de aquella capital las herbolarias con el mismo nombre vulgar.

Es un poderoso vulnerario, como lo acre. ditan diariamente sus buienos efectos, lavando las ulceras, aunque provengan del virus sifilitico, con su cocimiento, y aplicando la yerba en polvo, come se ha dicho de la Capitaneja. Dicha planta es la que describe el Dr. Ilemandez, pag. 11 , tom. 3.0 con el nombre de Nanahuapatli, ò medicina del morbo gàlico, en donde asegura que cogiendo un puñito de la yerba, quebrantàndola y tomándola con un licor conveniente, las veces que fuere necesario, destruye de raiz el mal venereo, y cura las úlceras y tubérculos que se manifiestan en toda la superficie del cuerpo. 


\section{Palancapatli, de Puebla. (Doronicum Glutinosuni,} W.-Grindelia Glutinosa, Dun?)

Es muy frecuente en los contornos de esta capital, donde se hacen de esta planta los mismos usos que se han dicho del Palancapatli, de Mléxico.

\section{Palo mulato. (Schinus, F. M. I.)}

Nace con mucha abundancia en los montes de Veracruz.

El cocimiento del len̄o y corteza de este árbol, se usa interiormente, $y$ en lavativas, en tierra caliente, para curar el vòmito prieto. Tambien se da á beber el zumo de los cogollos con el mismo fin. En los paises frios se usa el mismo cocimiento para las fiebres pútridas.

En Puebla gastan comunmente por palo mulato, el tronco de un arbustito que cultivan en algunos jardines, y es la Cineraria Precox, Cav., la que es muy diferente del citado palo mulato, y es de creer que sea lo mismo en cuanto á sus propiedades.

Pepitas de Sopilote. (Swietenia Mahagoni, $L_{n}-$

Se cria por Acapulco, y otras partes de tierra caliente. 
El fruto de este árbol, dice el mismo Hernandez, que es grande, oblongo, y que encierra unas semillas planas y pectorales, que se parecen en el sabor á las almendras amargas, aunque despues dejan un olor de almizcle $y$ un sabor fetido: que sus virtudes son semejantes á las de dichas almendras, y que resuelven los tumores maravillosamente, ablandan la tos, suavizan el pecho, é introducidas en las narices descargan la cabeza: aprovechan igualmente en las úlceras: tambien su aceite espreso suaviza y limpia el rostro. Las antiguas mexicanas lo usaban ya como cosmético.

Lavando la cabeza con el cocimiento de las semillas quebrantadas sin descortezar, sirve para curar los granos y estinguir la caspa de ella.

Su semilla descortezada acostumbran mezclarla en la preparacion de los jaboncillos de olor, que se hacen en esta Capital para lavar la cara y manos.

Su leño es rojo, duro, pesado, y muy apropósito para pulimentarse. Los ingleses y americanos usan ésta madera para muebles por su hermosura y duracion.

Palau, dice, que su leño sirve para teñir de color negro pardo. (Práctica de botánica de Linneo, tom. 3. ${ }^{\circ}$ pag. 551.)

Pimienta de T'abasco ó Malagueta. (Myrtus Pimenta, L.-Xocoxochitl. Hern.)

Nos viene del Estado de su nombre. 
Las bayas son aromáticas, estomacales, cefalicas, estimulantes y tonicas. y pueden sustituirse en la medicina y en el nso dietetico, por las demás pimientas.

En la historia natural de este regetal, escrita por el Dr. D. Casimiro Gomez Ortega, é impresa en Madrid el año de 1780 , se verán con mayor estension sus usos y virtudes, con otras noticias relativas al mismo vegetal.

\section{Piña. (Bromelia Ananas, L.)}

Nos viene generalmente á Puebla, de Còrdova y sus contornos

Su fruto es bien conocido de todos, apetecido y ponderado con justa razon por todas las naciones. Promueve el apetito, corrobora el estòmago y contiene los vòmitos. Se usa en los dolores nefríticos y en las snpresiones de orina. Se tiene tambien por un poderoso antihelmintico, y con este motivo se da á las criaturas para arrojar las lombrices. Con el zumo se hace un jarabe, que mezclado con agua, sirve de un refresco agradable.

\section{Piñones de indias. (Jatropha Curcas, L.)}

Se recogen de un árbol que crece en Apacingàn $\mathrm{y}$ en otras tierras semejantes, segun noticias de los botánicos que fueron destinax? 
dos á las espediciones facultativas. Tambien se da en Cordova, segun noticias del Sr. Dr. Llave.

Las semillas son tan acres que abrasan, drasticas é inflamatorias, y por lo mismo no deben usarse interiormente, sino con mucha precaucion.

El aceite del Croton tiglium parece ser el mismo que producen dichos piñones, segun el analisis de Pelletier y Caventou practicado en 1818, como puede verse en el formulario para la preparacion $y$ uso de varios medicamentos nuevos de Magendie, pag 179. En tal concepto parece no habrá necesidad de estar puramente atenidos al que nos venga del estrangero, por tener proporcion de sacarlo en la República. En caso de no ser los pin̄ones de nuestra Jatropha curcas, los mismos que los del Croton tiglium, que se cria en la india oriental, Islas de las Molucas, y Cochinchina, seria siempre conveniente hacer un ensayo con aquellos, pues siendo tan anàlogas las propiedades de ambos piñones, parece que tambien deben ser iguales los efectos.

Plumagillo ó Milenrama. (Achillea Millefo-

Se cria en algunos jardines y huertos, y crece espontaneamente por el cerro de S. Juan, de Puebla. 
Se recomienda mucho esta planta en los casos de atonía nerviosa: se asegura que ha producido buenos efectos en las leucorreas rebeldes, en los cólicos ventosos, en la hipocondria \&c. (Alibert: Nouveaux elemens de Therapeutique $\&$ c $c$, citados.)

Fis una de las plantas que entran en la composicion del agua del Papa.

\section{Pochote ó Pochotl. (Bombax Orientale, Spreng.-} Bombax pentandrum, $L$.)

Crece por Matamoros, Còrdova, y otros pun. tos análogos de la República.

El zumo de la raiz, dice el Dr. Hernandez que es útil á los febricitantes.

\section{Pochotl. (Vease Pochote.)}

\section{Prodigiosa. (Athanasia Amara, F. M. I.)}

Se da en la hacienda de Tlascolpam, y en otros montes cercanos á Puebla.

La infusion y el estracto de esta yerba, se usan como febrifugos y estomacales: este se ministra en pildoras, $y$ en dosis de cuatro á seis granos, por mañana y tarde; y aquella en la cantidad de media libra á las mismas horas, recomendàndola además para contener las diarreas provenidas por debilidad de estòmago $y$ falta de digestion. 


\section{Raiz del gato. (Vease yerba del gato.)}

\section{Raiz del manso. (Helianthus Glutinosus. F. M. I.)}

Crece en los montes de San Angel, de Tlalpam, y cerro de Tepoxuchitl cerca de Puebla. Su raiz es tuberosa, cilindrica y central, de una cuarta hasta media vara de longitud, de un blanco que tira à amarillo en lo interior, y por fuera de un pardo mas ó menos oscuro, y estriada. Cortándola fresca, despide un olor parecido al de la trementina, $y$ un jugo que se pega á los dedos como ella: seca, conserva su olor aún mas vivo, y los bordes de las incisiones se presentan resinosos, resistiéndose á la pulverizacion aunque esté muy seca. Fit tallo es herbaceo, crece hasta tres pies, sencillo, cilindrico, aspero, peloso. Las hojas radicales, unas, son acorazonadas, de tres gajos con el del medio mas largo, aovado-eliptico, y agudo: otras, entre acorazonadas y angulosas: todas festonadas, ásperas, y escurridas por el pezon, que por lo regular es igual â ellas. Las del tallo son parecidas á las radicales, con el pezon muy corto. Los pedùnculos son axilares, de un pie ó mas de largo, cilindricos, mas gruesos por la parte superior, y en su superficie ásperos como el tallo, y de una sola flor, Las hojuelas del caliz son algo recargadas, aovadas, agudas y pestañosas. Los semifiosculos son lanceolados, escotados, de una mitad mas 


\section{7}

largos que el caliz, y de un color morado claro que tira al de violeta.

iAcaso podrá pertenecer á otro gènero por no convenir mucho con el caliz del Helianto, $y$ tambien porque el color de los scmiflosculos no es propio de las especies de este genero?

Su raiz es balsámica, pectoral, y muy vulneraria. Esta raiz es la que los indigrenas conocen con el nombre de liga, y la usan machacada para afirmar las articulaciones, despues de haber reducido los huesos dislocados; para acelerar las cicatrizacion en las heridas, y mundificar las úlceras. Los mismos, segun noticia del Padre D. José Ramirez de Alzate, llaman tambien á esta planta Tlalpopolotl, y es sin duda la que describe el Dr. Hern. en el tomo 3.0 de su obra, pag: 153, con el nom. bre de Tlacopatli o Quauhtotollanensi, en donde espresa que el cocimiento aprorecha en las disenterias, y escita el apetito á los que padecen naùseas. El mismo Padre Alzate dice: "Los progresos de la cirugia tan solamente se consiguen en virtud de hechos prácticos: un indio del barrio de Santa María (Curato de Cuernavaca), de oficio cortador de madera, con la hacha se rajó una canilla: de esto le resultò una gangrena; por lo que fué perdiendo la pierna poco á poco, ya el estrago se verificaba en el muslo, separada la rodilla, cuando un indio curandero lo libertó de una muerte muy proxima, tan solamente con aplicarle en polvo el Tlalpopolotl un poco tostado. EI Tial- 


\section{8}

popolott es to que los arrieros conocen por liga (á causa de que los Indios cazan pájaros untando varitas que colocan en los sitios correspondientes); con ella curan las mataduras ó llagas que se forman en los lomos de las béstias empleadas en cargar. Es una raiz tuberosa que se cria con abundancia en la Sierras vecinas á esta Ciudad. iA que usos no podrá aplicarse en beneficio de la humanidad?" (1).

\section{OBSERVACIONES.}

Al ver el jugo resinoso que presenta esta raiz fresca cortada en pedazos, y tambien algunas gotas á manera de trementina que se manifiestan en varios puntos de la corteza puestas á secar las raices enteras, dió motivo á practicar con ella algunos esperimentos químicos, por medio de los cuales se obtuvieron de cien partes de la misma raiz seca, los productos siguientes,
Resina..............12, 11 .
Sustancia gomosa.........15, 62.
Id. estractiva.......... 46,87 .
Residuo leñoso..........23, 06.
Deficit..............02, 34.

El color de la resina es de un pardo de clavo; su olor, aromático suave que se acerca algun tanto al de azafran; sabor al principio

(1) Gaceta de México, número 5 de 15 de marzo de 1788. 
amargo, despues acre, de un picante que se siente en la boca por bastante tiempo, promoviendo la salivacion.

La sustancia gomosa es parecida en el color á la resina, aunque con algo mas de amarillo; olor, semejante al de la miel cocida; sabor, al principio dulce, y al fin amargo muy ligero. La sustancia extractiva es de un color pardo, con puntos amarillentos; olor, semejante al de la sustancia gomosa, sabor al principio casi insipido, luego ligeramente astringente, se pega á los dientes, tarda algun rato en disolverse, y tiñe la saliva de un color amarillo bajo.

Resta, pues, observar las virtudes de cada una de estas sustancias, y dar oportunamente noticia al público de ellas, despues de haberse cerciorado bien los profesores de medicina que se encarguen de tan interesante trabajo, en obsequio de la humanidad, $y$ de los progresos de la Terapeutica y Materia médica.

\section{Rosilla. (Commelina Tuberosa, L.)}

Es muy comun en la República.

Se usa, como varias especies del mismo género, en los mismos casos que la yerba del pollo (vease esta), y á mas su flor sirve para varios usos económicos, como para teñir papel de azul \&ce, y la infusion de ella es un reactixo equivalente á la tintura de violeta. 


\section{SEacatechichi. (Vease Simonillo.)}

\section{Simonillo ó Sacatechichi. (Baccharis Amara, Cerv,-Erigeron Graphalivides, $K$ ?)}

Kis muy comun en los contornos de Puebla. La raiz es fibrosa, central, del largo de dos pulgadas, del grueso de una pluma de gallina, de color blanco que tira á amarillo, y con fibrillas en toda su longitud. El tallo es herbaceo, derecho, que crece hasta un pie ò mas, cilindrico, sencillo en la parte inferior, y con ramos alternos en la superior: sus hojas, alternas, lineares, con dientes algo profundos desde la mitad hasta la punta, que abrazan algo el tallo, y revueltas. Las flores en forma de panoja, en número de tres ó mas en cada ramo, con los pedúnculos de una flor terminales: las bracteas, lineares y agudas. Las flores her$m$ afroditas se hallan mezcladas con las femeninas, que es uno de los caractéres del género Baccharis de Linneo, al cual se ha agregado el género Molina de Ruiz y Pavon, cuyo caracter es tener las flores dioicas, $\mathbb{K}$.

Toda la planta es tomentosa y presenta un color blanquecino.

Su sabor es muy amargo, cuya cualidad la recomienda para que los profesores se empeñen en observar sus virtudes, pues hasta ahora solo se sabe que la usan vulgarmente Pasa corregir las fiebres intermítentes, hacien. 
do una infusion en una libra de agua con dos dracmas de la misma yerba, y. tomándola en ayunas en cantidad de 4 á 6 onzas por algunos dias.

Finé de Veracruz. (Bidens Leucantina, W-Coreopsis Leucantha, $L$.)

Nace en las cercanias de dicho puerto, $y$ es muy comun en otras partes de lo República.

Los catalanes fueron los primeros que principiaron á trasportar esta planta á España con el referido nombre de Té de Veracruz, y la buscaban con empeño cuantos barcos llegaban al mismo puerto procedentes de Cataluna.

Tiene un olor aromatico agradable despues de seco, y es un buen estomático. Se usa en los mismos términos, y para los mismos fines que el Té de China.

\section{Tecomate. (Tease Cuteuteconale.)}

5. Tejocote. (Crataegus Mexicana, F. M. I.)

Es muy abundante en todos los montes, y con porticularidad en los del camino de Mexico. Los frutos y semillas son astringentes y corroborantes. Dan abundante jalea que se dispone en un dulce agradable para la mesa.

El cocimiento de su raiz se usa en la hidropesia como aperitivo y desobstruente. 


\section{2}

\section{Tepozan. (Vease Topozan.)}

\section{Tescalama. \{Ficus Nympheifolia, $L$ )}

Nace en tierra caliente.

El uso mas comun de esta resina es aplicarla en parches en la cadera, como un poderoso glutinante, cuando las mugeres esperimentan flujos de sangre, ò propenden á los abortos por debilidad de ella. Aplicase igualmente, en la misma forma, en las luxaciones de huesos, sobre las quebraduras ò hernias, tanto en los adultos, como en los parvulos; y tal vez es preferible para este último caso, al celebrado Ocuje de la Havana, que no siempre se consigue puro, y sí á un precio subido.

\section{Tlacopatli. (Aristolochia Mexicana, F, M. I.)}

Crece en la Misteca, de donde la traen Ios indigenas á esta capital con abundancia. Su raiz es de un olor aromático fuerte, de la cual se hace grande uso para los dolores flatulentos sin irritacion, y tanto que la piden con el nombre de raiz para el flato en algunas partes.

Puede ser un buen sucedaneo de la Serpentaria Virginiana (Aristolochia Serpentaria, L.), por pertenecer al mismo género. 


\section{Tlanepaquelite. (Vease Yerba Santa.).}

\section{Toloache. (Vease Yerba hedionda.)}

\section{Topozan ó Tepozan. (Budléa Americana, L.)}

Es árbol muy comun y conocido de todos. El Dr. Hernandez, tom. 2. ${ }^{\circ}$ pag. 107, lo recomienda por un buen uterino, diurético y mundificante, surtiendo igualmente buenos efectos en las llagas atónicas y en las quemaduras.

\section{Tragacanto del pais. (Cactus Tuna, et Cactus. Opuntia, L.)}

Ambas especies abundan mucho en la República.

La concrecion que se cria en dichas dos especies de tuna, y de que dio noticias en sus gacetas de literatura el Padre D. José Alzate, llamándola Alquitira de la tierra, tiene muchas propiedades de la goma tragacanto ò alquitira del comercio (Astragalus Tragacantha, L.), y puede sustituirse por ella en todas las composiciones en que la prescriben los autores, sin embargo de que su disolucion en agua no es tan perfecta.

Se halla en pedazos ya arredondados. ya aplastados por la superficie, y algo cónca- 


\section{4}

vos por la parte inferior, en la que está pegada alguna corteza del nopal á que estaban adheridos. Su color, de un amarillo rojizo á manera del incienso; olor $y$ sabor poco perceptibles. Puesto un grano en la boea y meneandolo entre los dientes, se ablanda con lentitud formando mucilago. Se rompe dificilmente con el martillo, y es dura para pulverizarse,

\section{Trinitaria. (Fiola Trico?or, L.)}

Se cultiva en varios jardines y huertos. Sus flores se tienen par emolientes y anodinas. Las hojas son tambien emolientes, y su raiz dicen algunos autores que es purgante y emética, y que las semillas promueven la orina y el vòmito.

\section{Tiliompetilla. (Vease Moictle.)}

\section{Tumbirichis. (Brometia Pinguin, L.)}

Se producen de Cordova para abajo, y en otros temperamentos análogos.

Cuando sus frutos estan sazonados se estrae la parte carnosa, de la que se saca el zumo, con el cual se hace un jarabe en nuestras boticas, y se usa diluido en agua comun como antiescorbutico, habiendose aplicado tambien con favorables efectos á los diabéticos. Śe asegura igualmente que quita la embriaguez, lo mismo que el álcali volatil, 


\section{Tzonpanquahuit!. (Vease Tronpantli.)}

\section{Tzonpantli ó "T'zonpanquahzitl.} (Erythrina Corallodendrum, L.)

Es árbol muy comun en los contornos de México y Orizava.

Las hojas escitan los menstruos, y la corteza es astringente.

Su madera es may usada en lugar del corcho (Quercus Suber, L.), de la cual se hacen tapones como de este, y se destina para otros usos mecánicos.

\section{Ule. (Castilloa Elastica, F. M. I.)}

Es un árbol que crece en las costas calientes de la Repùblica, y particularmente por la del rumbo de Veracruz. Tambien to hay en la hacienda de San José del Corral, de Cordova.

Su resina, recien estraida del árbol, està liquida y de un color lechoso, en cuyo estado sirve para varios usos econòmicos, y tambien para formar candelillas, pesarios $y$ otros instrumentos elàsticos, que se usan en la cirugia. Tambien se preparan con esta resina liquida, algunas telas de seda, lino ó algodon, de que hace uso la medicina en plantillas, botas \&ce., para promorer el sudor y disipar los edemas. 
Puede verse la descripcion y estampa de este àrbol en el dišcurso pronunciado por $\mathrm{D}$. Vicente Cervantes en 2 de junio de 1794, en México, para la apertura del curso de botánica, inserto en el suplemento á la gaceta de literatura de la misma capital, el 2 de julio del propio año.

\section{Violeta del país. (Sida Triloba, Cav.)}

Es comun en los alrededores de Puebla, y otras partes de la Repûblica.

Es planta que pertenece á da familia de las malvaceas, y su virtud es emoliente, como lo son estas.

En algunas partes Ia usan en lugar de la Violeta (Viola odorata, L.). Esta flor es una de las que se se conocen por cordiales en la farmacia, y convendria que los profesores observasen si puede sustituirse por la del país, en cuyo caso tendriamos la ventaja de conseguirla mas fresca y aprecio mas comodo.

\section{Xiloxochitl. (Inga Pulcherrima, F. M. I.)}

Nace en los contornos de Puebla, y es muy diferente del Xiloxochitl de Hern. (Carolinea Princeps, L.)

El cocimiento de su raiz y sus hojas se usa por agua á pasto en laś fiebres agudas y catarrales, y se ministra tambien en lavativas. 


\section{Xoxocoyoli ò Xoxocoyollin. (Oxalis Violacea, L.)}

Se halla por todas partes con la Oxalis Stricta, L., á la que se da tambien el mismo nombre vulgar.

Ambas son refrigerantes y producen buenos efectos en el escorbuto, calenturas putridas é inflamatorias, y pueden sustituirse por la acederilla (Oxalis acetosella, L.), y por la acedera (Rumex acetosa, L.)

\section{Xoxocoyollin. (Vease Xoxocoyoli.)}

\section{Yerba de la alferecia. (Vease Junquillo)}

\section{Yerba del Angel. (Eupatorium Sanetum, F. M. I.)}

Es frecuente en los contornos de México. Se tiene por un escelente estomacal, vulnerario y febrifugo, y segun noticias se usa en México.

\section{Yerba de las animas. (Vease Chapuz.)}

Yerba del Cancer, de-México. (Lythrum Vulnerarium, Gomphrena Procumbens, F. M. I.)

Segun noticias se usan en México estas dos especies de distintos géneros con aquel nombre. 
La primera nace en todas las acequias, $y$ aseguran las gentes del campo que machacada, cruda ò cocida, y aplidada á las úlceras cancerosas, las sana en pocos dias: y la segunda se cria en el pedregal de San Angel, y los pastores y demás gente del campo afirman haber sentido con ella buenos sucesos en las llagas cancerosas, lavándolas con el cocimiento, y aplicando la yerva en forma de cataplasma. Seria conveniente observarlas por los facultativos para reconocer exactamente si son, ó no, ciertas las virtudes que se les atribuyen.

\section{Yerba del Cancer, de Puebla. (Vease -Yerba del Pastor.) \\ Yerba del Cura.}

En México es de uso frecuente, y en Puebla adonde vienen de aquella capital solamente sus hojas, que son de un aroma suave, parecido al del laurel, empieza á tener alguno para los dolores reumáticos, artriticos y en la gota, aplicándola en baños; y se asegura ser un buen vulnerario.

Lerba de la doncella. (Begonic taberosa, F. M. I. -Begonia gracilis, Kunth?)

Crece en los alrededores de Puebla, barranca de Santa Fé, y pedregal de S. Angel.

Por algun tiempo se turo por la Begonia balmisiana, de que Ja se ha hablado; pero ha- 
biéndose examinado con más detencion, convinieron los botánicos de las espediciones facultativas en que eran especies diferentes, atribuyéndoles iguales virtudes, aunque mas remisas las de la tuberosa.

El Dr. Hernandez llama á esta planta Totoncaxoxocoyollin, y dice que la infusion de la raiz escita la orina, purga los intestinos $y$ aprovecha en las inflamaciones de los ojos.

Yerba dulce. (Lippia dulcis, F. M. I.-Lippia Graveolens, $K$ ?)

Se cria por Orizava y Còrdova, de donde viene á Puebla.

Es bastante usada por los profesores de medicina; cuyo cocimiento parece lo aplican como emenagogo; y los profesores, encargados de las salas de observaciones de México, la colocaron entre sus demulcentes.

Yerba y raiz del gato. (Valeriana Phú, L.)

Nace en las cercanias de Puebla, como en Coronanco, hacienda de San Isidro y la Cienega.

El sabor de su raiz es amargo, y el olor fétido, á la que se inclinan mucho los gatos, por lo cual sin duda se la diò este nombre. Se tiene por diurética, sudorifica y antiespasmodica, y puede usarse para el mismo efecto 
por la oficinat, en la epilepsia, convulsiones, histérico, y demás enfermedades en que se aplica esta.

El cocimiento de aquella raiz se reco. mienda mucho para cicatrizar las úlceras inveteradas, lavándolas con él, y echando despues su polvo encima de ellas.

\section{Yerba de la gobernadora, de México.} (Zygophyllum, Cerv.)

Viene á México de tierradentro, adonde se da en parages frios.

Primeramente la colocaron los botánicos de la espedicion faeultativa en el género Cisto, llamándola Cistus dichotomus, y posteriormente nos aseguró D. Vicente Cervantes que correspondia al espresado género Zygophyllum. Segun noticias se cria en ella una especie de panalito que aunque chico, es idéntico en sustancia al del comejé.

Es muy celebrada para curar el reuma. tismo, los dolores artríticos, y fortalecer los nervios: en todas estas enfermedades se administran los baños de la yerba, ó se fomenta la parte débil con su cocimiento.

Yerba de la gobernadora, de Puebla. (Eupatorium Veronicaefolium, K.-Tiene caractères que se aproximan á los del gènero Rosalesia ex Llav. et Lex. Fasciculus 1. pay. 9.) particularmente en el cerro de Guadalupe. 


\section{1}

En esta capital se hacenl los mismos usos de esta yerba, que los que se han manifestado en la anterior de México, y siempre prefiriendo la nuestra.

No obstante convendría hacer observaciones por los profesores sobre sus virtudes, para poderlas fijar con exactitud.

Yerba hedionda ó Toloache.

(Datura Stramonium, $L_{u}$ )

Nace en todas estas cercanias.

Es narcotica; pero usada con las precauciones que previenen Stork y otros médicos, aprovecha en las convulsiones, mania, epilepsía y otras enfermedades, sirviendo tambien en las ùlceras cancerosas y quemaduras.

\section{Yerba del negro. (Malva Angustifolia, Ait.)}

Se produce por Huamantla.

La tintura alcoholica bien cargada de la yerba, se usa en friegas para los dolores reumáticos, y el mismo uso tiene hirbiendola en agua y bañandose en su cocimiento.

Yerba del pastor, y del cancer de Puebla. (Acalipha Prunifolia, K.)

Es muy comun en todos los contornos de Puebla. 
Se tiene por vulneraria y detergente, y por este motivo se aplica con frecuencia su cocimiento para lavar las llagas, echando despues su polvo sobre ellas.

Esta misma planta es la que tambien se gasta en Puebla por la del cancer.

\section{Yerba del perro. (Vease Yerba de Puebla.)}

\section{Yerba del pollo. (Tradescantia Erecta, Cav.)}

Es bastante frecuente en la República. Se tiene por vulneraria, y se usa su cocimiento como tal, en enjuagatorio, para las llagas de la boca; y tomado á pasto, para la leucorrea, úlcera uterina, $\mathrm{y}$ en la hemoptisis.

\section{Yerba de Puebla ò del perro.} (Scnecio Canicida, E. M. I.-Yizcuinpatli, ó venena de perros, Hern tom. 2. pag; 401.)

Su raiz es fibrosa, compuesta de fibras sencillas, cilindricas, centrales, del grueso de una pluma de gallina, y con su superficie pardusca. El tallo es herbaceo, derecho, de tres pies de altura, sencillo, cilindrico, con felpa blanquecina, que tira à pardo-rojiza, en su base, y el resto algo peloso. Hojas, alternas, entre sinuosas y almenadas, y las lacinias con dientes agudos, de un verde claro por su superficie, blanquecinas y nerviosas por el envés, con algun vello, como tambien sus pezones, que son 


\section{3}

cortos y acanalados. Sus flores son terminales, de color amarillo naranjado, dispuestas en corimbo, y en nümero por lo regular de seis, con los pedúnculos largos, estriados y vellosos, y bracteas lineares Toda la planta despide un olor pesado.

NOTA. Sutlen encontrarse hojas angulosas en la parte superior del tallo.

Nace cerca de Puebla en la hacienda de Tlascolpam, de donde se trae con abundancia á esta Capital, y en ella se hace su reposicion à fin de remitir á tierradentro para matar lobos, y otros animales cuadrúpedos que perjudican á las reses.

Es con particularidad un veneno poderoso para matar los perros, como lo indican los nombres mexicano $y$ latino que se le han aplicado, en los cuales se ha observado que ya envenenados, dan carreras con mucha precipitacion, atropellando cuanto encuentran, y estas son alternadés con tírarse al suelo y con convulsiones mas ó menos violentas, hasta que al fin mueren, ó bien en la carrera, ó en una de las eonvulsiones: ademas babean y sacan la lengrua, como se les advierte cuando tienen mucho ealor.

Sin embargo de producir los efectos indicados en los cuadrúpedos, puede usarse su infusion, preparada con dos dracmas de la yerba en una libra de agua caliente, tomada en tres ocasiones al dia, para promover la traspiracion, segun observacion de algunos facultatisos. 
Yerba Santa ó Thanepaquelite. (Piper Sanctum, F. II. I.)

Nace en Orizava, y climas análogos de la República.

Parece ser el piper obliquum de Ruiz y $\mathbf{P a}$ von, y el Tlancepatli de Hern. Este dice que los antiguos mexicanos lo usaban en sus alimentos, y en el dia lo hacen con el Tlanepaquelite en varias partes, mezelándolo en algunos guisados.

Es aromática, estimulante, estomática y odontalgica, y se usa para los flatos. Por la destilacion da un aceite volátil mas pesado que el agua, y muy parecido al de sasafrás, por el que puede sustituirse.

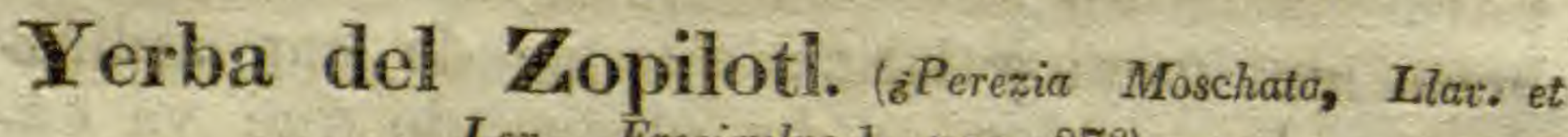
Lex., Fasciculus 1. pag. 27?)

Nace en los montes cercanos á Morelia, donde la conocen con el nombre de cola de Zorra, segun el Sr. Lejarza.

Toda la planta despide un olor muy fuerte de almizcle. Puede considerarse como corroborante y estomacal, como lo son las plantas de su género; y ademas debe gozar de propiedades antiespasmòdicas, como el almizcle, por parecerse á este en su olor. Yerba del tabardillo. (Piqueria trinervia, Cav.)

Es muy comun en todos los contornos de Puebla. 
Es aromática, estomática $y^{5}$ febrifuga, de cuya última cualidad tomò aquel nombre por usarla con mucha frecuencia y con feliz sucen só, los indigrenas, en los tabardillos y demás fiebres ardientes.

\section{Verba del Lorillo. (Croton Diocus, Cav, $-C_{0}{ }_{0}$ ton Vulpinum, F. M. I.)}

Palmar.

Nace por Acacinco y $\mathbf{S}$. Agustin del

Se usan la raiz y semillas de esta planta: aquella, reducida á polvo y ministrada en la dosis de media dracma, hace purgar con bastante violencia y aun vomitar: estas, en número de treinta, machacadas y hecha una emulsion en dos onzas de agua comun, purgan con suavidad, $y$ en ocasiones promueven tambien el vòmito. $\mathrm{I}$ por lo mismo conviene usar tanto la raiz, como las semillas, con la debida precaucion, arreglando sus dosis á la edad y robustéz de los enfermos.

\section{Yoloxochitl. (Magnolia Glauca, L.)}

Crece por Cuernavaca, Córdova, y en la hacienda de S. Miguel sobre rio blanco.

Sus semillas se consideran como antiepilepticas, haciendo una infusion con dos dracmas de ellas en ocho onzas de vino, del que se 
dan á los enfermos dos cucharadas por Ta mañana, $y$ otras dos por la tarde. Tambien se forman píldoras de las mismas semillas, y se ministran, en cantidad de medio escrupulo, cada tres horas.

\section{Zoapatle. (Vease, Cihoapatti,)}




\section{7 \\ REINO ANINAL.

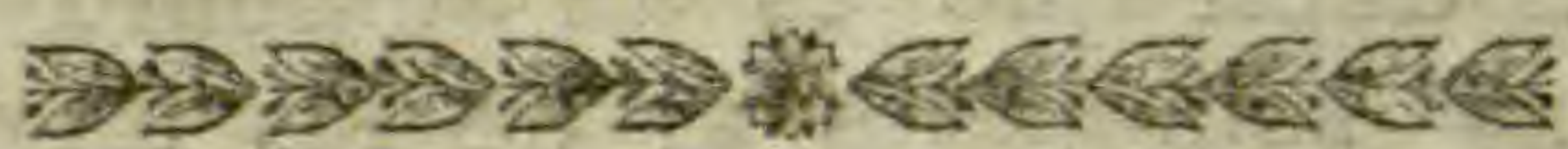 \\ Ajolotes. (Salamandra Mexicana.)}

Se sabe que los profesores de las esper diciones facultativas de esta República los dieron la denominacion espresada; pero sin haber visto su descripeion, ni tampoeo se tiene cono, eimiento de los principios en que se apoyaron para darsela, pues 'L. (1) habla de la Salamandra, solo como especie de Lucerta.

Posteriormente hemos visto la descripcion y anatomia del Ajolote, en la parte segunda do las obrás del Baron de Humbolt y Bompland, observaciones de Zoologia y Anatomia comparada, tom. 1.0 pag. 112 y siguientes, donide despues de haber observado este, el Proteo y la Sirena, se concluye con decir que de estos tres animales dudosos, uno solamente, á saber el Ajolote, debe ser borrado del catálogo de los animales, y considerado como una larva, por: cuya razon en la lámina 12 del eitado tomo, en que está grabado, lo llana Proteus seu larva Salemandrate. Canvendria que los naturalistas mexicanos observasen si efeetiramente es tua larva, ò si un animal perfecto.

(1) Systema Naturae, tom I. Pars III. pag: 1060 
El Dr. Hern. (1) to llama Axolotl poniendo tambien su estampa y descripcion, la que concluye con decir que es un alimento saludable, agradable, y semejante al de las ánguilas, ma. nifestando en seguida los varios modos de condimentarlo para usarlo como tal.

Se crian en las lagunas de México, en cuya capital los gastan tambien en el dia como alimento, y por ser inocente se vé recomendado su uso para los enfermos atacados de obstrucciones inflamatorias de higado (2).

Tambien se prepara un jarabe con su parte gelatinosa, un cocimiento de yerbas pectorales y la cantidad snficiente de azucar, recomendado en las enfermedades de pecho cuando estan indicados los medicamentos pectorales mucilaginosos. (3)

(1) Edicion romana, pag. 316

(2) Disertacion sobre dicha enfermedad del Dr. D. Joaquin Pio Eguia y Miruro, pag. 21, premiada por el Protomedicato de México.

(3) Estandose imprimieudo este Ensayo, tuvimos la oportunidad de ver la parte 2, perteneciente al año de $\mathbf{1 8 2 4}$ de las Philosophical Transactions of the Poyal Society of Eondon, de que se halla la esposicion sobre los organos de la generacion del Proteo Mexicano por el año (pag. 419 á 423), y por ella consta que el

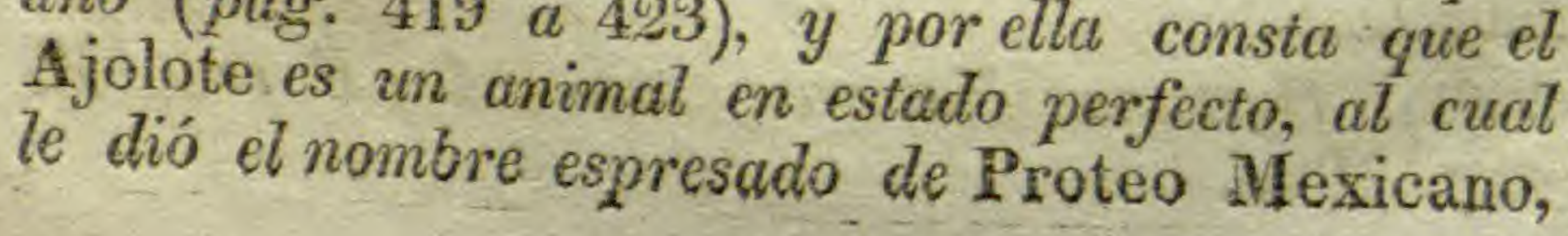




\section{9}

\section{Axi ò Axin.}

Con este nombre se conoce una sustancia mantecosa, amarilla, correosa, de olor parecido al de gordura rancia, sacada por medio de la decoccion en agua, de unos insectos que se dan en varios árboles de tierra caliente, de cuya sustancia hacen diver'sos usos los indigenas; y se recomienda para mitigar los dolores que aflijan cualqniera parte del cuerpo, para aflojar los nervios rigidos y suavizarlos, resolver los tumores, ó madurarlos cuando propenden á la supuracion: aprovecha al fin de las erisipelas, en las úlceras, en las convulsiones, y mezclada con resina, en la quebradura llamada Enterocele (1). In el dia usan muchos indigenas esta sustancia para los Espermaioceles, y agregándola trementina, ule, polvos de sueldaconsuela $y$ arrayan, forman bizmas, que se aplican las mugeres en la cadera con el fin de fortifiearla, y contener los flujos de sangre.

Omitimos hablar por menor de dichos insectos $y$ de algunas particularidades relativas á ellos, por saber que en México se está trabajando sobre esta materia.

á concecuencia del examen prö̈jo que hizo de varios individuos llevados de aqui por Mr. BuHock, en los que hallò completamente desenvueltos los sexos masculino y femenino, de lo gue pone tres escelentes láminas, que son la 21, 22, y 23.

(1) Hern. eaicion romana, $7 i b$. II, cap. $F$. fol. 317 . 


\section{Comejen, ó nido de Perico.}

Es una sustancia que se nos trae de tierra caliente, cuyo color es pardo que se asemeja al café tostado, compuesta toda de celdillas irregulares, formadas en capas, y con agugeros interiores que desde luego sirven para el transito de los insectos que la fabrican, Hamados tambien vulgarmente Comejen: es inodora; pero al fuego produce una llama blanca y permanente hasta su reduccion á cenizas, y entonces despide un olor semejante al de la paja ó madera quemada.

La forman al pie de los àrboles y en masas de bastante volumen (hasta de dos varas) y diversas figuras, unos insectos que corresponden al genero Termes de L., y segun la prolijas observaciones que de ellos hicieron $\mathbf{D}$. Vicente Cervantes y D. José María Bustamante, se persuadieron que era la especie destructor de dicho género.

Tambien el Comejen se conoce con el nombre de nido de Perico porque esta ave suele fabricar en aquel su nido, en cuyo caso es una misma sustancia conocida con ambos nombres.

El que gustare imponerse mas por menor de la historia natural del Comejen podrá ocurrir al Observador de la República mexicana, tomo $2.0^{\circ}$ número 8 , pag. 276 , impreso en Mé-
xico 1827 . 


\section{1}

Se usa la espresada sustancia para sahumar á las criaturas acometidas de alferecia, y á las personas adultas insultadas, ó que padecen convulsiones nerviosas:

\section{Vibora de cascabel. (Crotalus Horridus, L.)}

Desentrañada, cortada la cabeza y cola, y despojada de su piel, se usa reciente para hacer su caldo segun previenen las farmacopeas.

Su corazon é higado, á quienes se les da el nombre de Bczoardico animal, suelen usarse por algunos facultativos, y con mas frecuencia su enjundia y piet, en la que se estienden algunos emplastos cefálicos para las sienes.

El tronco, ó la vibora seca, reducido á polvo, se gasta como sudorifico y dulcificante de la sangre. 


\section{REINO MINERAL。}

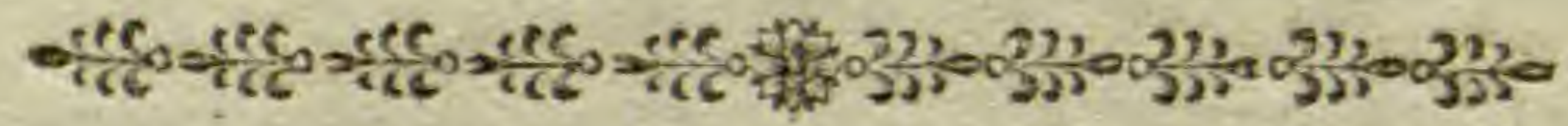

Tierra de Villerias ò de la hacienda de San Nicolas, de donde se trae.

Esta tierra, á la que llamò Bol gris D. Manuel Cotero, catedrático de quimica que fué de México, diò por el analisis que el mismo hizo de ella las sustancias siguientes.

De Siliza.............47,00,

De Alumina.............. 19, 00,

De Magnesia............. 06, 20.

De Cal................. 05, 40 .

De Hierro ............... 05, 40 .

De Agua................ 17, 50 .

Los cincuenta cien avos sobrantes, se calcularon de oxidacion en las operaciones.

En el hospital de San Pedro de esta Capital de Puebla, la usan echando dos dracmas en polvo para cada libra de agua ò púlqne, haciendo tomar esta infusion á los hidròpicos, auxiliándolos al mismo tiempo con otras medicinas apropiadas para destruir dicha enfermedad. 


\section{3 \\ NOTR.}

Aunque la República mexicana es tan abundante en produceiones minerales, sin embargo, como las de uso medicinal se hallan espresadas en Ias materias médicas, nos hemos limitado por lo mismo á tratar solamente de la tierra de Villerias, tanto por ser poco conocida hasta el dia en las boticas, como pormanifestar las sustancias de que se compone, en justa memoria del benemérito profesor de química que la analizó; y solo sí diremos de paso que en el Palmar de la hacienda de D. Roque á legua y media de Chietla, hay un terreno que da en abundancia la Sal Catartica (Sulfato de Magnesia), que si se beneficiase en grande, podria surtirse de ella la Republica, en cuye caso no habria necesidad de la estrangera, á la que no cede en calidad. 


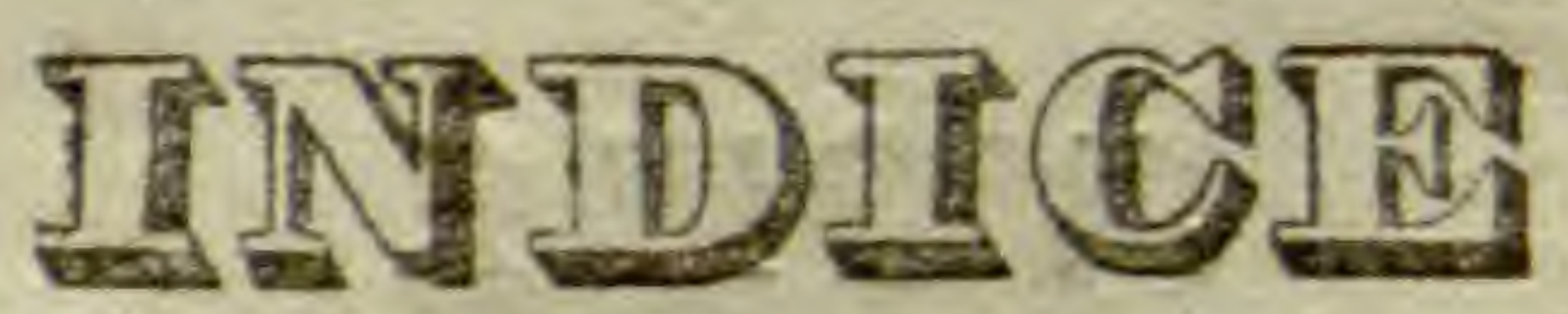

\section{de los nombres vulgares correspon- dientes á los genéricos y específicos, de las plantas ya espresadas.}

Nombres Vulgares.

Nombres genéricos y especificos. Pág.

\section{A}

Abelmosco..............?

Algalia.................

Alfilerillo.................. Geranium Cicutarium ......... Alquitira del país............Cactus Tuna, Cactus Opnntia..02. Aquequesqui................ Arum? ................. 02 . Arbol del Perả.............. Schinus Molle............. 03. Archipin.................. Burseria? Gummifera .........04. Atlanchan. Cuphea Lanceolata...........05.

\section{B}

Barbudilla............... Dorstenia Contrayerba........06, Begonia.................... Begonia Balmisiaña...........06,

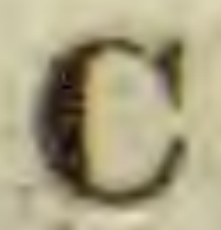

Cabezuela................. Centaurea Cyanus...........08. Cacahuate. . . . . . . . . . . Arachis Hipogaea ........... 08 . Capitaneja ............. $\left\{\begin{array}{c}\text { Platypteris Crocata, Bibens } C_{\text {ro- }} \\ \text { cata, Spilanthus Crocatus.... }\end{array}\right.$

Capuchina ................ Tropeolum Majus............ Cebolleja ................ Veratrum Sabadilla............

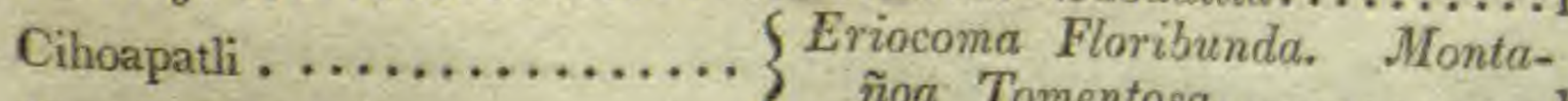
Ciruelo del país............. Spondias Myrobalanu........ Copal blanco............... Heliocarpus Copalifera........... Cuajilote............... \{ Crescentia Musaecarpa. CresCuauch centia Edulis? ...,.........12.

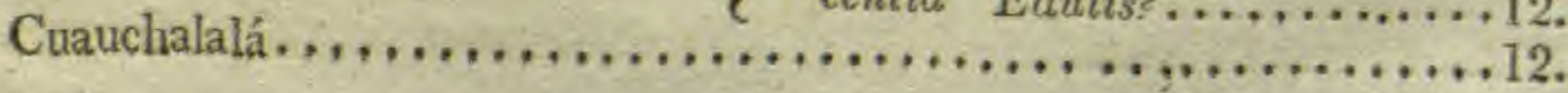


Nombres Vulgares. Nombres genéricos y específicos. Pag.

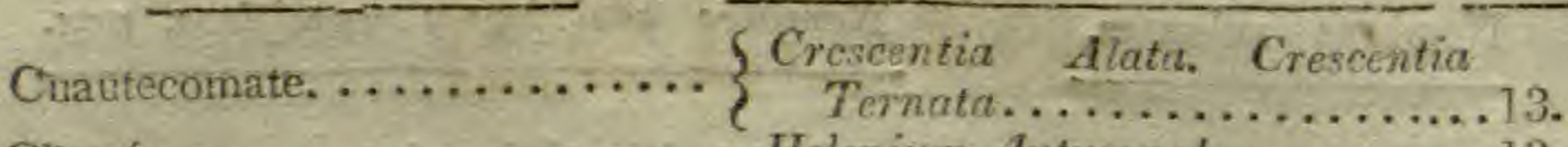

Chapúz.,................. Helenium Autumnale ......... 13.

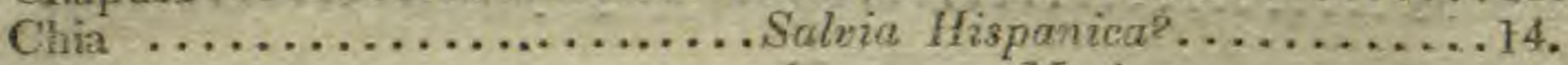

Chicalote ................. Argemone Mericana.........14.

Chicozapote ............... Achras Sapota ............. 15.

D.

Damiana................... Cineraria Mexicana......... 15 .

E

Epasote.................Chenopodium Ambrostnides....15. Epazotl.................... Chenopodinim Anbrosiordes....16. Espinosilla. .................. Hoitzia Coecined............16.

\section{F}

Falsa pimienta............ Schinus, Nolle......... 16 . Flor de encino, dé,México.......Tillandsia Lingulata.......... 16. Flấ de encino, de Puebla...... Querculs :................17. Flor de pascua .............. Euphorbia Heterophilla......17.

\section{G}

Goma de Sonora ............ Laceae Species? ........... 18 .

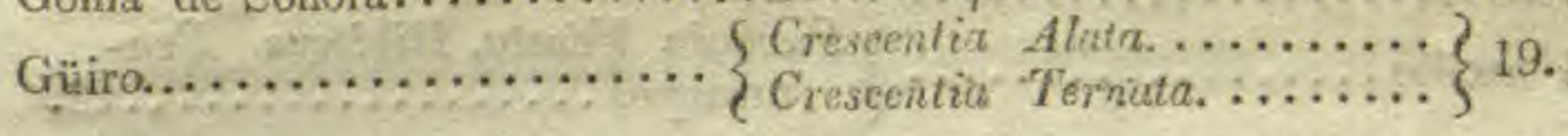

\section{H}

Haba de Indias.............. Hurd Crepitans.............19.

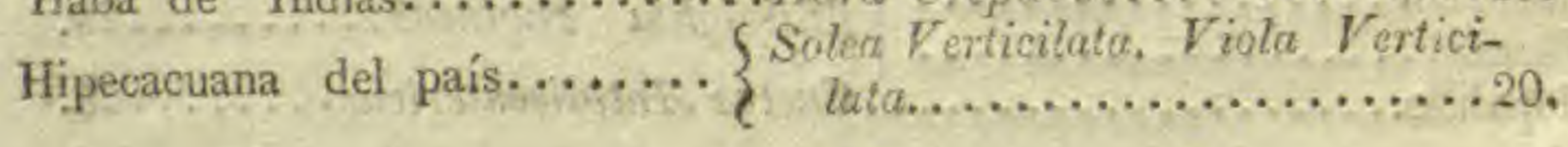

\section{J}

Jaltomate................. $\left\{\begin{array}{l}\text { Saracha Dentata. Atiopa Den- } \\ \text { tata .................... }\end{array}\right.$

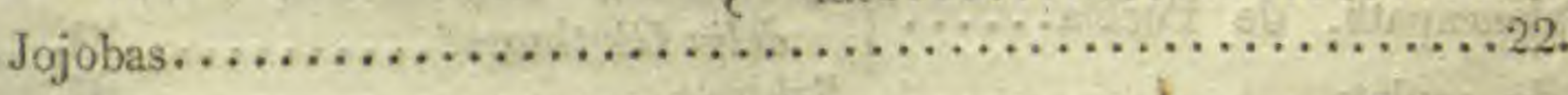


Junquillo .

Cacius Flageliformis ..........22.

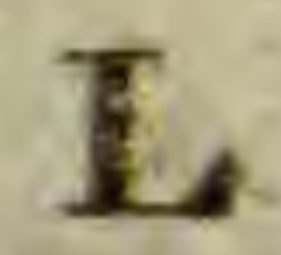

Lignoaloe $\ldots \ldots \ldots \ldots \ldots \ldots$ Linanué.$\ldots \ldots \ldots \ldots \ldots \ldots$. Amyris?,$\ldots \ldots \ldots \ldots \ldots \ldots \ldots$,

\section{M}

Maguey.................... Agave Americana..........23. Malagueta.................. Myrtus Pimenta. ..........24. Malva de Veracruz........... Sida Caponsis. .............24. Mamey................. $\left\{\begin{array}{r}\text { Lucuma Mammosa.Achras Mam- } \\ \text { most.................... }\end{array}\right.$ Mangle................. Rhyzophora Mangle...........25. Maravilla ................. Mirabilis Jalappa .........26. Mastuerzo de Indias........... Tropaeolum Majus.............27. Mercadela................. Calendula Officinalis..........27,

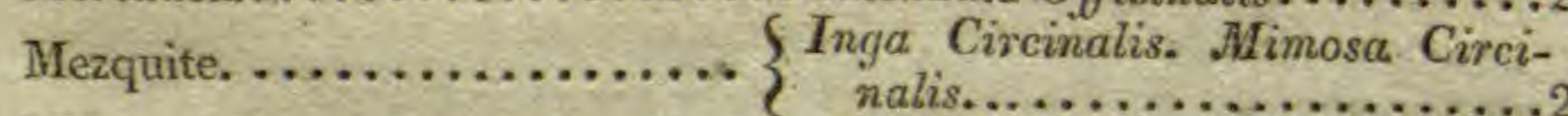

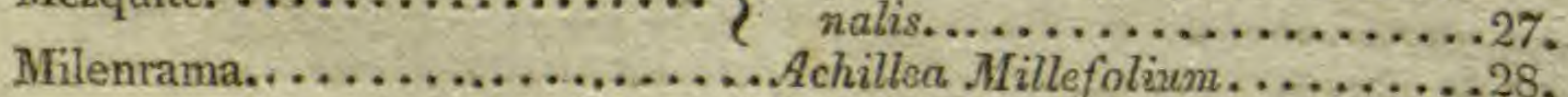

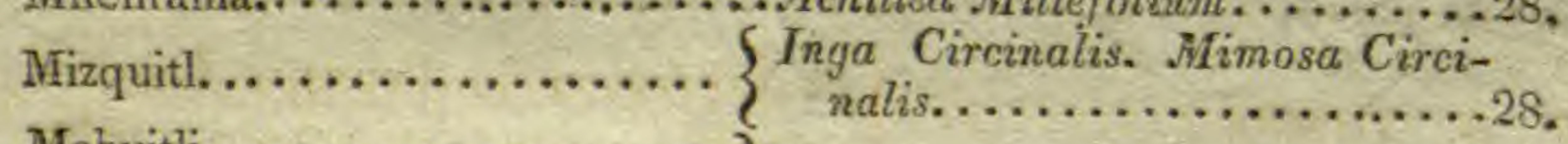
Mohuitli............... Moictle................... Monacillo............... $\{$ Pavonia Veneta. Hibiscus Pentacarpos.................28.

N

Nananchi ................. Nanchi. Malpighia Faginea? $\ldots \ldots \ldots \ldots 29$. Nopahillo.................. Cactus Antidisentericus.......29.

$\mathbf{P}$

Palancapatli, de México......... Solidago Montana............30. Palancapatli, de Puebla...... $\mid$ Doronicum Glutinosum. GrinPalo mulato 1 delia Glutinosa? ............. 31. Pepitas de Zopiloti.............. Swietenia Mahagoni............. 


\section{7}

Nombres vulgares. Nombres genéricos ys esperificos. pag.

Pimienta de Tabasco........... Hyrtus Pimenta............32. Piña..................... Bromelia Ananas................. Piñones de Indias............ Jatropha Cureas...............33. Plunagilio................. A chillea Millefolinm...........31. Pochote................. | Bombax orientale. Bombax penPochotl. tandrum ................. Prodigiosa....,................ Alkanasia Amara...........

\section{Bi}

Raiz del Gato............. Valerinna Phu........... 36 . Raiz del manso............. Helianthus Givizosus .........36. Rosilla ................. Commelina Tuberosa .........39,

\section{3}

Sacatechichi............ \{ Baccharis Amara. Erigeron Gna-

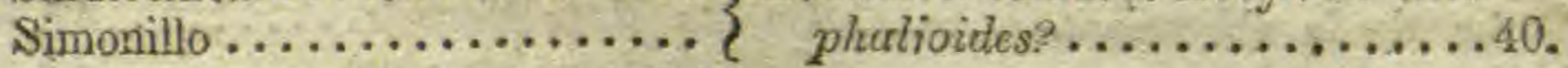

\section{T}

Té de Veracruz........... S Bidens Leucantha. Coreopsis LeuTe de Veracraz........... Tecomate Crescentia Alata. Crescentia tor-

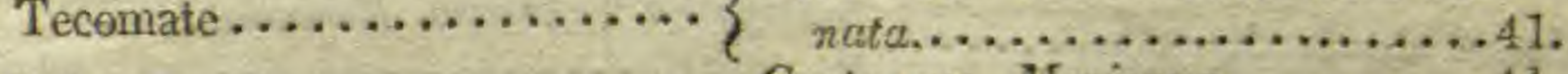
Tejocote................... Crataegus Mexicana.......... Tepozan....................Budleia Americana...........42. Tescalama,.................. Ficus Nympheif folia.........42. Tlacopatli....................Aristolocibia Mexieana.......42. Tlanepaquelite .................. Piper Sanctum.............43. Toloache. ................ Dexurd Stramonizm.........43. Topozan....................Budleia Americann.........43. Tragacanto del pais........... Cacius Tunt. Cactus Oprntia..43. Trinitaria ................. Viold Tricolor..............44. Trompetilla..................Justisía Tinctoria ...........44. Tumbirichis ............... Bromelia Pingtin ..........44. Tronpanguahuitl............ $\{$ Eryilhrina Corallodendrum, ....45. 


\section{8}

Nombres vulgares.

\section{$\mathrm{U}$}

Ule.

Castilloa Elastica.

45.

V

Violeta del pais............. Sida Triloba............. 46.

\section{$\mathrm{X}$}

Xiloxochitl.................Ingo Pulcherrima..........46.

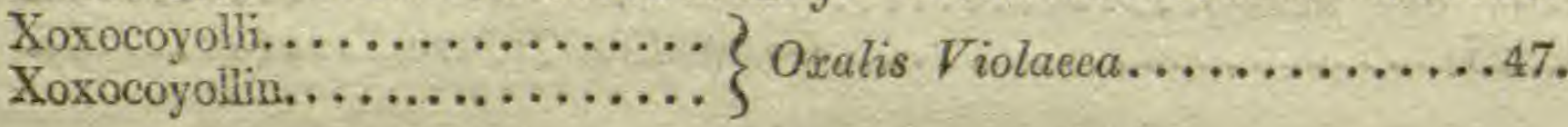

\section{$\mathbf{Y}$}

Yerba de la alferecia......... Cactus flageliformis $\ldots . \ldots \ldots 47$. Yerba del àngel............. Eupatorium Sanctum,........ 47 . Yerba de las ànimas...........Hetenium Autumnale.........47.

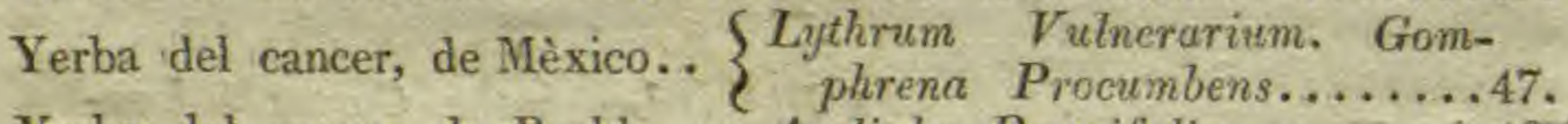
Yerba del cancer, de Puebla.....Acalipha. Prunifalia.......... 48 . Yerba del cura ................................... 48 . Yerba de la doncella........ $\left\{\begin{array}{l}\text { Begonia Tuberosa, Begonia Gra- } \\ \text { cilis...................... }\end{array}\right.$ Yerba dulce............. \{ Lippia Dulcis. Lippia Grave-

Yerba del gato.............Valeriana Phù............... 49 . Yerba de la gobernadora, de Mè-? xico.................

Yerba de la gobernadora, de Puebla.................... Zygoplyllum..............50. Eupatorium Veronicaefolium,...50. Yerba hedionda................ Datura Stramonium..........51. Yerba del negro..............Malva Anqustifotia ..........51. Yerba del pastor.............. Acalipha Prunifolia...........51. Yerba del perro............... Senecio Canieida $\cdots . . . . . . . .52$. Yerba del pollo................Tradescantia Erecta ...........52.

Yerba de Puebla................ Senecio Canicida. ............52. Yerba Santa...............Piper Sanetrm.............54. Yerba del Zopilotl..............Perezia Moschata?.............54. 
Nombres vulgares:

Nombres genéricos y especificos. pag.

Yerba del tabardillo.

Piqueria Trinervia...........54. Yerba del Zorrillo.......... \{ Croton Dioecus. Croton Vulpi-

Yoloxochitl. .................Magnotia Glauca...

$$
\text { 18? Z Z }
$$

Eriocoma Floribunda. Monta-

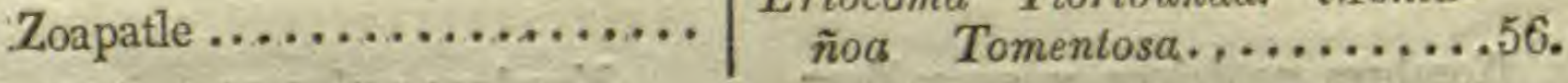

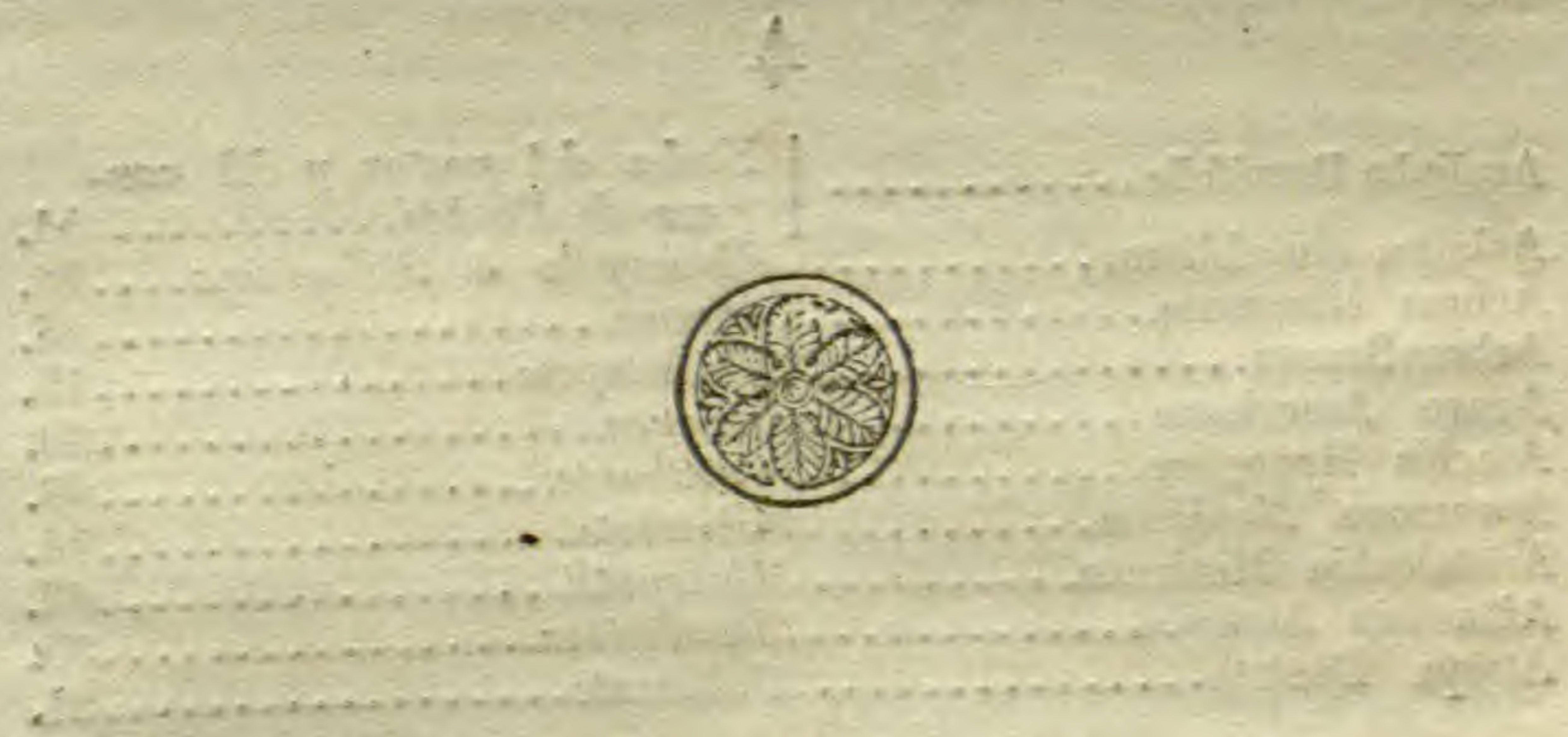




\section{IRNDIDICI}

de los nombres genéricos y especéffcos, correspondientes á los xulgares, de las plantas ya espresadas.

Nômbrés genéricos y específicos.

\section{A}

Acalipha Prunifolia........... $\left.\right|^{\text {Yerba del pastor, } y \text { del ean- }}$ Achillea Millefolium de Prebla............51. Achras Milieforium............. Plumagillo ò Milenrama ....34.

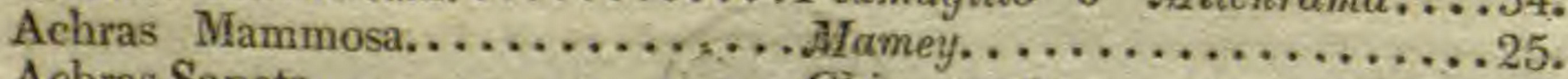
Achras Sapota . ................ Chicozapote ................. Agave Americana ..............Mfgquey...................23. Arachis Hypogaea .............. Cacaluate,................. 08. Argemone Mexicana............ Chicalote ...................... 14 , Aristolochia Mexicana. .........Tlacopatli..................42, Athanasia Amara ..............Prodigiosa................. 35 . Atropa Dentata...............Jaltomate ...................21.

\section{B}

Baccharis Amara, ............. Simonillo of Sacaiechichi, ....40, Begonia Balmisiana............... Begonia. ...................06. Begonia Tuberosa............ Y Yerba de la Doncella $\ldots . . . . .48 .4$. Bidens Crocata................. Capitaneja.................. 09 . Bidens Leucantha.............Te de Veracruz................4. Bombax Orientale............ $\mid$ Pochote o Pochotl ...........35. Bromelia Ananas. ................Piña......................33. Bromelia Pinguin, .............Tumbirichis ......................44. Budleia Americana .............. Topozan d Tepozan............43. Burseria? Gummifera, .,...........Ahrchipin..................,04. 


\section{C}

Cactus Antidisenterieus, .......... Nopalillo ..............29. Cactus Flageliformis........... \{ Junguillo o yerba de la alfe-

Cactus. Onuntia.............. $\}$ recing Cactus Tuna............... Tragacanto det país........43. Calendula Officinalis..............Mercadela................. Castilloa Elastica. ............. Ule................... 45. Centaurea Cyanus .............. Cabezuela.................08. Cineraria Mexicana. ............ Damiana................ 15. Commelina Tuberosa............ Rosilla..................39. Coreopsis Leucantha............Tè de Veracruz...........41. Crataegus Mexicana. ........... Tejocote. . . . . . . . . . . . . Crescentia Alata............... Cuatecomate d Tecomate, Güiro.13.

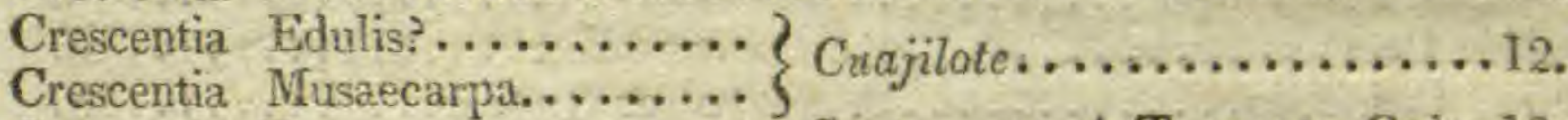
Crescentia Ternata............... Cuatecomats a Tecomate, Gürro.13. Croton Dioecus.............. Yerba del Zorrillo..........55.

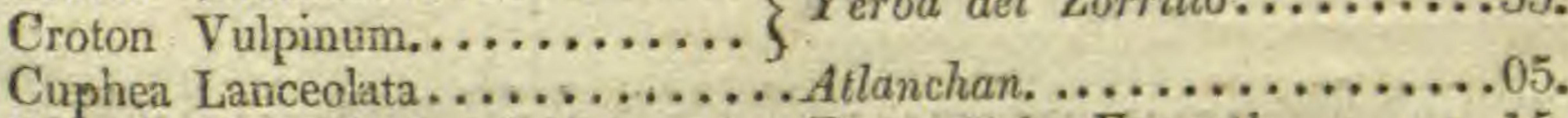

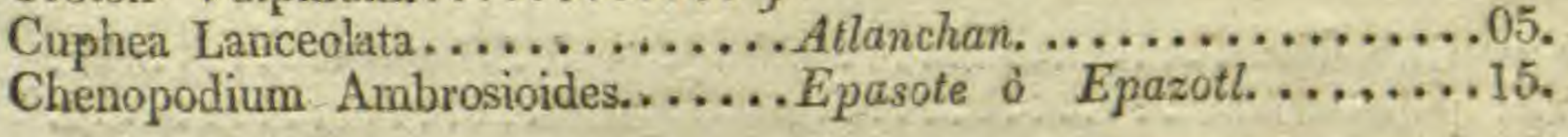

\section{D}

Datura Stramonium............ Yerlsa hedionda ò Toloache...51. Doronicum Glutinosum...........Palancapatti, de Puebla.....31. Dorstenia Contrayerba, ..........Barbudilla............... 06.

\section{E}

Erigeron Pnaphatioides?.......... Sinonitlo ó Sacatehichi.....40. Eriocoma Floribunda............ Cihoapatli ó Zoapatle......10. Erytrina Corallodendrum.........Tzonpantli d Tzonpanquahuitl.45. Eupatorium Sanctum...........Y Yerba del Angel.........47. Eupatorium Veronicaefolium.... $\mid$ Yerba de la gobernadora, de

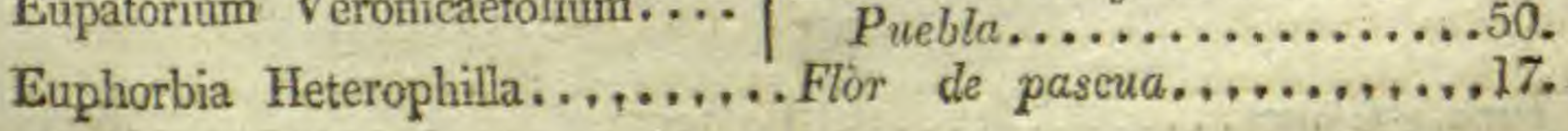


Nombres genèricos y especificos. Nombres vulgares. pag.

\section{F}

Ficus Nimpheifolia.

Tescalama.

\section{G}

Geranium Cicntarium ............Alfiteriblo.............. Gomplirena Proctmberis.......... Y erba del Cancer, de México.47. Grindelia Giutinosa?............Palancapatti, de Puebla.....31.

\section{H}

Helenium Autumnale........... Chapuz $\delta$ yerba de las inimas.13. Helianthus Glutinosus........... Raiz del mansso............ 36 . Hibiscus Abeimoschus, ........... Abelnosce of Algalia .........01. Hibiseus Pentacarpos............Monacillo................28. Hoitzia Coccinea ............... Espinosilla ...............16. Hura Crepitans................Maba de Indias ............. 19.

\section{I}

Inga Circinalls. ...............Mezquite o Mizquitl......27. Inga pulcherrima. ............ Xiloxochitl. .............46.

\section{J}

Jatropha Curcas .............. Piñones de Indias..........33.

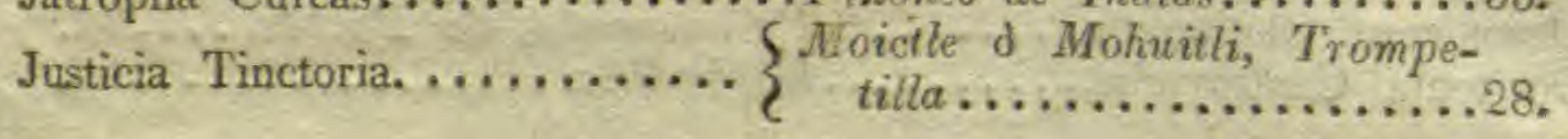
L.

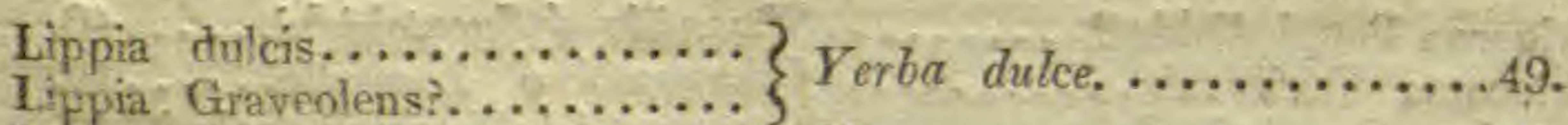
Ite ma Mammosa..............Mamey...............25. Lythrum Vulnetarium. ..........Yerba nel Cancer, de México.47.

\section{M}

Magnolia Glavea ............... Yoloxochitl ..............55. Nialpighia Faginea?...............Nanchi ó Nana. chi.............. 
Nombres genéricos y específicos. Nombres valgares. pag.

Malva Angustifolia............ Yerba del Negro............5I. Mimosa Circinalis.............Mezquite d Mizquitl.......... Mirabilis Jalappa. .............Maravilla..................26. Montañoa Tomentosa............ Cikodpatti o 'Zoapatle...........

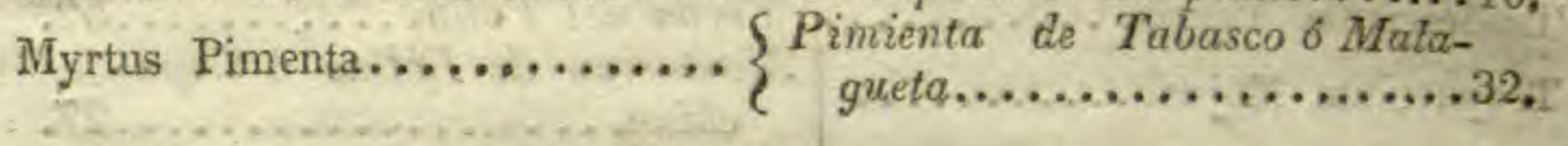
(9)

Oxalis Violacea.,............ Xoxocoyoli 6 Xoxocpyollin...47.

\section{$\mathbf{P}$}

Pavonia Veneta..............Mondéllto................28, Perezia Moschata?............. Yerba dal Zopilotl..........54. Piper Sanctum.............. Ferba Sania 6 Tlanepaquelite. 54. Piqueria Trinervia............. Yerba del Tabardillo.........54. Platypterís Crocata.............Capitanija ...............09.

\section{Q}

Quercus ..................Flor de Encino, de Puebla..17.

\section{$\mathbf{R}$}

Rhyzophora Mangle, ............Aangle.................

\section{S}

Salvia Hispanica?.............Chia ................. 14 . Saracha Dentata.............. Jaltomate..............21,

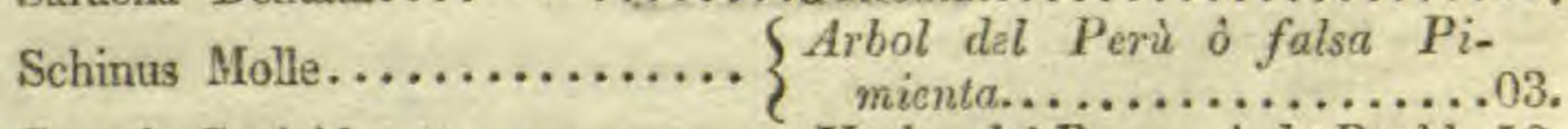
Senecio Canicida.............. Yerba del Perro, ò de Puebla.52. Sida Capensis.................Malva de Veracruz.........24. Sida Triloba................. Violeta del paìs........... 46. Solea Verticilata...............Hipecacuana del paìs........20. Solidago Montana.............Palancapatli, de Mexico......30. Spilanthus Crocatus, ........... Capitaneja................ 09 . Swietenia Mahagoni.............Pepitas de Zopilotl..........31. 
Nombres genericos y especificos. Nombres vulgares, Pag.

\section{$\mathbf{T}$}

Tillandsia Lingulata.............Flor de Encino, de México..16. Tradescantia Erecta. ............ Yerba del Pollo.............52. Tropaeolum Majus............. $\mid$ Mastuerzo de Indias ó Capuchina...................27.

\section{V}

Valeriana Phú................. Yerba y raìz del Gato .....49. Veratrum Sabadilla............... Cebolleja ................. 10. Viola Tricolor ...................Trinitaria...................4. Viola Verticilata.................Hipecacuana del pais.......20.

\section{Z}

Zygophyllum................... Yerba de la Gobernadora, de. México.................5.

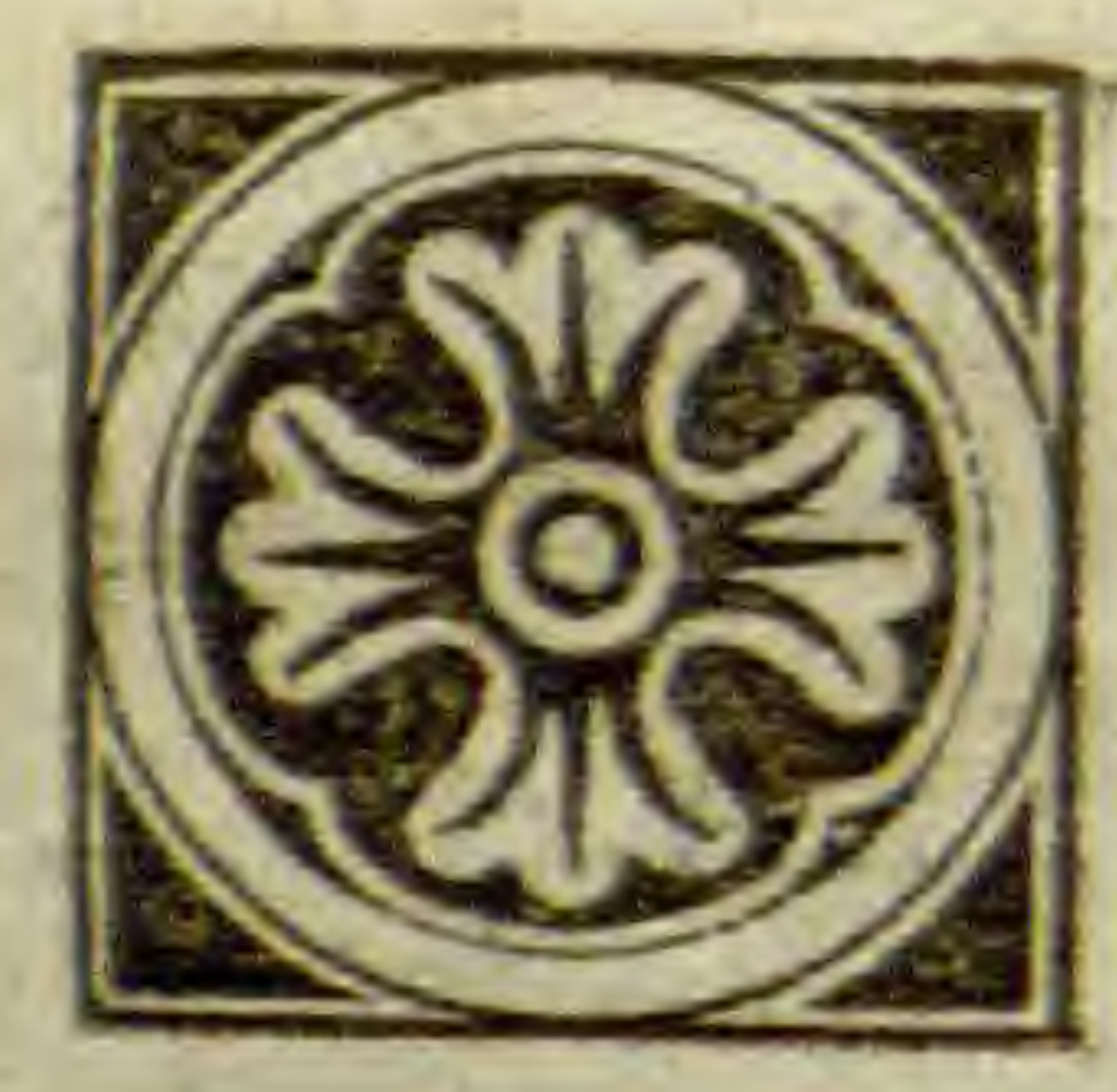




\section{5 SUCEDANEOS.}

能

Achicorias. (Cichorím Intybus, $\boldsymbol{L}$.)

La raiz de la Achicoria amarga que se usa en algunas boticas de la. República, es la de la Cardencha (Dipsacus fullonim, L.), cuya sustitucion convendria abolir, gastando en su lugar la de la Lechuguilla [Sonchus oleraceus. L.] por corresponder esta y las achicorias á una misma clase y órden.

La raiz y hojas del diente de Leon (Leontodon taraxacum, L.) Ilenarian completamente las indicaciones de la achicoria, pues por fortuna se halla ya bastante propagado en México y Puebla, y se verificaria lo mismo en toda la República, sembrando su semilla, porque nace facilmente.

La Lechuguilla es muy comun en todas las tierras cultivadas.

\section{Ajenjos. (Artemisia Absinthium, L.)}

Por esta especie se usa la Artemisia laciniata. F. M. I. , conocida vulgarmente con el 
nombre de Estafiate, cuyas virtudes se ha observado que son iguales.

Et Estafiate se cultiva en las huertas, y nace espontaneamente en los campos.

Los tallos de esta planta, cultivada, crecen hasta 6 pies: son esponjosos, derechos, estriados, casi sencillos en la parte inferior, y ramosos en la superior, con los ramos axilares, dispersos, sencillos, y gradualmente mas cortos hacia la punta del tallo, $y$ en todo conformes con este. Sus hojas son igualmente dispersas, sentadas, laciniadas, con las lacinias lineares y agudas, lampiñas por la parte superior, y tomentosas par la inferior: las de los ramos, sencillas, lineares, con las mismas notas que las lacinias de las del tallo. Infloresencia, en espigas terminales $y$ axilares, alternas $y$ mas cortas que la hoja, con las flores unilaterales y cabizbajas. Bracteas, entre lancealadas y lineares, y agudas. Receptáculo desnudo. NOTA. Las plantas silvestres que se han observado convienen con los caractéres de la cultivada, á escepcion de su tamaño, que casi es la mitad, y su tallo enteramente simple en la parte inferior.

Almendras amargas. (Variet. Amygdali communis, L.)

En lugar de estas se gastan en las baticas las pepitas ô almendras del Durazno [Amygdalus persica, L.], las que son abundantes en la República, y un buen sucedaneo. 


\section{7}

Como estas pepitas suelen darse à las criaturas para las lombrices, es conveniente advertir que deben usarse con mucha precaucion, no pasando de una ó dos al dia, pues se ha verificado la muerte de alguna de aquellas por esceso de la dosis, en razon del acido hidrocianico que contienen (Virey.)

\section{Alquimila ó pata de Leon. (Alchemilla Vulgaris, L.)}

Se sustituye en nuestras boticas por esta planta un geranio, llamado por L. Geranium alchimilloides, cuyas virtudes, segun las observaciones de los facultativos, son las mismas que las de la Alquimila.

Se encuentra por los contornos de Puebla.

\section{Altea. (Althaea officinalis, L.)}

Se gasta en las boticas por raiz de altea Ia corteza de una matva [Malra Vitifolia, Car.], cuyos efectos corresponden á la altea ó malvavisco, con la diferencia de ser mas abundante de mucilago que este, y por lo mismo se tendrá la precaucion de disminuir la dosis de la corteza en los cocimientos, que deben ademàs herbir muy poco.

Es abundante en los alrededores de Puebla. 


\section{8}

- Artemísa. Artemisia Vulyàris, L.

Por esta planta se usa la Ambrosia Artemisifotia, $\mathbb{L}$., acaso con ventajas en sus virtudes.

Crece por todas partes.

\section{Bardana. (Arctím Lappa, L.)}

Se acostumbra gastar en algunas partes por esta raiz el platanillo [Canna Indica, L.], muy diferente en todo de la bardana, y por consiguiente mal sucedaneo.

En el jardin botánico de Mèxíco se habia propagado, y fomentando su cultivo podrian surtirse de ella las boticas, sin necesidad de valerse de otra planta distinta, ni de ocurrir tampoco á la estrangera.

\section{Betónica. (Betonica Offïinalis, L.)}

Por esta especie se gasta la Betónica alopecuros, L. y se considera preferible, tanto por su mayor aroma, como por abundar en la República.

\section{Butua ó pareira brava. (Cissampelos Pareira, L.)}

Suele despacharse por esta raiz la de la parra silvestre [Vitis labrusca, L.], abundante en Atlixco y Orizava, cuyo uso convendrá desterrarse de las boticas, (si aun existe tal prac- 
tica), por creerse poco conformes las virtudes de esta raiz con las de aquella.

Es planta perenne de la América meridional, y tambien la hallaron en esta Repùblicá los naturalistas de las espedieiones facultativas, y es de esperar que multiplicándose los conocimientos de la botánica, se pueda encontrar acaso con abundancia, ahorrandose de este modo la necesidad de gastar la que viene por el comercio.

\section{Calaguala, (Polypodium Plitlitidis, L.)}

Esta raiz se cria en la América meridional, y se conoce en las boticas con el nombre de Calaguala del Perú á mas de esta se - gasta en ellas otra, llamada Calaguala del pais, que es tambien perteneciente á un polipodio y cuya especie aun no ha podido determinarse; pero que en cuanto à sus virtudes, segur la obser,vacion general de los profesores, es igual á la del Perú.

La del pais nace en los montes cereanos á México, á donde la llevan con abuadancia, en tiempo de aguas, los yerberos.

\section{Cardo santo. (Centaurea Benedicta, L.)}

Si todavia se sustituye en las boticas, como se practicaba en otro tiempo, con el chicalote (Argemone Mexicana, L.), debe dester- 
rarse de ellas un uso tan pernicioso; y en cuanto sea posible persuadir á las gentes del campo se abstengan de emplearlo por el $\mathrm{Car}$ do santo, à causa de los perjuicios que puede producir en las enfermedades que tratan de curar, pues al chicalote se le considera como corrosivo, y al Cardo santo como sudorifico y tonico.

Hallándose en el dia bastante propagado en Mléxico este ùltimo, no habria necesidad de ocurrir á ningun sucedaneo, y por supuesto nunca al chicalote.

\section{Cebolla albarrana. (Scilla Maritima, L.)}

Esta raiz exótica es de bastante uso en nuestras boticas, y lo es tambien la que en ellas se conoce con el nombre de Cebolla al barrana del pais (Pancratium Illiricum, L.), á quien se atribuyen las mismas virtudes, aunque mas remisas, y tal vez con el aumento de la dosis podrian ser iguales, en cuyo caso deberia preferirse el sucedaneo por ser muy comun en la República.

\section{Celidonia ó yerba de la golondina. (Chelidonium Mujus, L.)}

Sustituyen generalmente por esta planta, otra muy diferente, que es la Euphorbia $\boldsymbol{M} \boldsymbol{H}$ a culata, L. y abundante en la República. 
Una y otra son plantas lactescentes y algo causticas, y pueden tener bastante analogia en el modo de obrar. Esto se entiende en cuanto á su uso esterno, pues para el interno demanda mucha consideracion; y convendria no usarse dicha Euphorbia en los catarros, como vulgarmente lo acostumbran, sin un ensayo previo de sus virtudes.

La Celidonia mayor se ha propagado en el jardin botánico de México, y en el del Obispado de Puebla, y sucederia lo mismo en cualquier terreno análogo que se sembrase; y cuando esté propagada suficientemente no habria necesidad en ningun caso de sustituirle la espresada Euphorbia.

\section{Coclearia. (Cochlearia officinalis, L.)}

Esta planta se sustituye en Puebla por una pimienta, llamada por los indigenas Xolonacall, y vulgarmente Coclearia y borreguitos, cuya especie no ha podido determirarse. Convendria observarse por los facultativos para asegurarse de si sus virtudes son antiescorbuticas, como dicen generalmente.

En el dia se ha propagado tanto en Puedla el Lepidio (Lepidium latifolium, L.) que no habria necesidad de ocurrir á otra planta como sucedaneo de la legitima Coclearia, por ser el mas apropiado, y sus virtudes acaso superiores á las de esta. 
China. (Smilax China, L.)

Ws planta que habita en la China, el Japon y Persia, de donde se lleva á Europa su raiz, y es la que se gasta alli en la medicina. Se usa como sudorifica, antivenerea, y para la gota.

En esta Repúbliea no hay necesidad de ella por tener con abundancia otra raiz del mismo género, conocida con el nombre de Cocolmeca ó Cozolmecall (Smilax rotundifolia, L.) Es gruesa, casi redonda, roja y pesada cuando está fresca; pero en secándose es ligera, y de una testura fibrosa. Hablándo el Dr. Hern., tom. 2, pag. 42 á 44 , sobre las virtudes de esta raiz, las lleva hasta el estremo de la exageracion; y sin faltar á lo que acredita la esperiencia se le dan las mismas que á la citada raiz de China.

\section{Doradilla. (Asplenium Ceterach, L.)}

Hasta el dia no se ha encontrado esta planta en la República, y se usa en su lugar otra de diferente género, que llamaron los profesores de las espediciones facultativas $I y$ copodium Nidiforme, y solo una observacion prolija de los facultativos podrá decidir si es igual en sus virtudes á la verdadera Doradilla, pues hasta ahora no tenemos unos datos que lo confirmen; pero sabemos que en el público 
se usa, persuadidos de que produce buenos efectos en los casos á que se aplica, que son, segun ellos dicen, para refrescar y dulcificar la sangre.

Nace este Eycopodio en los parages montuosos y entre las piedras.

\section{Giscabiosa. (Scabiosa Arvensis, L.)}

Por la flor de esta planta se usan comunmente en las boticas las espigas de la Dalea gracilis, he Dalea sericea, Lag: Sus efectos parece que corresponden á los de la Escabiosa, por lo que en tal caso puede considerarse como un succdaneo apropiado.

Es muy comun en los contornos de Puebla.

Eiscorzonera. (Scorzonera Hispanica, L.)

Por la raiz de esta planta se gasta la de la yerba del Sapo [Eringium amethystinum, I.] cuya sustitucion está hecha con poca propiedad, pues aunque ambas convienen en la virtud diurética, se considera zdemás á la del Eringrio como emenagoga y afrodisiaca, virtudes de que carece la Esscorzonera.

La raiz de este Eringio, que abunda en la República, puede sustituirse con propiedad por la del Cardo corredor (Eringium campestre, $\mathbb{L}_{\text {..) }}$, que es el que se usa en la medicira. 
Por la raiz de Escorzonera convendria usar la de una especie de este mismo género, llamada Scorzonera mexicana, $\boldsymbol{F}$. $\boldsymbol{M}$. I., que es bastante comun en los contornos de Puebla y México.

\section{Estafiate. (Vease Ajenjos.)}

Gayuba. (Arbutus Uva Ursi, L.)

Mucho tiempo esturimos sin saber á que género correspondia la planta que se sustituye en nuestras boticas por la Gayuba, y aunque nos inclinabamos á creer que podia ser de su mismo género, no habiamos salido de esta duda hasta que observaciones posteriores confirmaron, que aunque no correspondia á él, sí era el Arctostaphylos pungens, $K$., género tan análogo al Arbutus, que se confundió en otro tiempo con él.

Un uso continuado por muchos años de esta planta, ha dado à conocer que sus virtudes son las mismas que las de la Gayuba.

Crece en Mora, Villalpando y Guanajuato.

\section{Goma de limon. (Amyris Elemifera, $L$.)}

Es planta de la Carolina, y de esta República.

Nos viene la resina en una masa sòlida, algo pesada, de distintos colores, sobresaliendo 
mas el amarillo verdoso, como el de limon, del cual parece haber tomado su nombre: por lo regular es impura, y su consistencia dé cera; su olor es fragante, y se acerca algo al del Galbano. Tiene poco uso en nuestras boticas, porque siendo mas puro, abundante, y de iguales ò mayores virtudes el Copal blanco, [Heliocarpus copalifera, L.], de que se ha hablado en su lugar, se prefiere en todas las composiciones en que entra la goma de limon.

\section{Gordolobo. (Verbascum Thapsis, L.)}

Esta planta se sustituye en las boticas por otra muy distinta, que es el Cnaphalium Indicum, L., $\tan$ diferente en figura, como en virtudes; motivo porque no conviene esta sustitucion, y seria mas apropiada la de alguna de las malvaceas, por considerarse emolientes y anodinas, que son tambien las principales propiedades del legítimo Gordolobo.

\section{Hisopo. (Hyssopus Offinatis, L.)}

Por esta planta se usa otra de diferente genero y clase, que se da con abundancia en los campos de Huamantla, de donde nos viene á Puebla.

Habiendola conseguido tresca pudo reconocerse bien su caracter genérico, y segun sus notas corresponde al genero Salvia, especie 


\section{6}

nueva, á la que D. Vicente Cerrantes, que tambien la reconociò, le puso el nombre de Pinearis por la figura de sus hojas.

Esta planta tiene la raiz leñosa, de un palmo de longitud, y del grueso del dedo pulgar, sencilla, central, de color pardo por defuera, y de un blanco oscuro en to interior, Sus tallos son casi leñosos, que crecen hasta la altura de un pie ó mas, derechos, articulados, algo angulosos y ramosos: los ramos entre alternos y esparcidos, algo vellosos y de la figura del tallo. Las hojas son lineares, sentadas, opuestas, enterisimas, agudas, y con puntos por ambas partes. Las flores, en rodajuela, de cuatro en cuatro, con pedùneulos cortos y violaceas. Las bracteas, acorazonadas concavas, puntiagudas, vellosas, (como lo son tambien el caliz y pedúnculos), de un color de violeta claro, y caedizas.

Toda la planta es algo aromàtica, y el olor se acerca al del Hisopo, y por esto, y porque sus efectos, segun ha acreditado la esperiencia, corresponden con los de este, parece ser muy buena sustitucion.

\section{耳aurel. (Laurus Nobilis, L.)}

Esta especie no se ha encontrado hasta ahora en la Riepública; pero se da en ella con abundancia el Laurus Indica, L., cuyas propiedades y virtudes son las mismas que las de aquella. 


\section{7}

Es abundante en los montes de Tlasco, de donde se nos trae á Puebla.

Rengua de Ciervo. (Asplenium Scolopendrum, L.)

Por esta planta se gasta en las boticas el Polypodium lanceolatiom, L., y por lo respectivo á su sustitucion, debe tenerse presente lo mismo que se ha dicho hablando de la Doradilla. Se da en los montes cercanos á Puebla.

\section{Wichen de Islandia. (Lichen Islandicus, L.)}

Se ha usado por esta planta con mucha frecuencia el Lichen con pyxides (Lichen pyxidatus, Li,) y aù en el dia lo gastan algunos facultativos; por lo que convendria observar bien sus virtudes, y en caso de ser semejantes, podria preferinse al Lichen de Islandia.

\section{Mecereon. (Daphne Mezereum, L.)}

En las boticas se gasta una planta conocida con el nombre de corazoncilla; pero se duda si será alguna especie del género Daphne, que debe darse en esta República, porque entre las medicinas corrosiras que se usaban en las salas de observacion de México, una de ellas era el Daphne laureola, (Mociño). 


\section{Mercurial. (Mercurialis Annua, L.)}

Esta planta se sustituye por otra muy diversa llamada Galinsogea parviflora, Cerv. W. Esta corresponde á la clase Singenesia, y aquella á la Dioecia; y no teniendo analogia entre si, es regular que tampoco la tengan en las virtudes, por cuya razon convendria hacer algunas observaciones por los protesores para asegurarse de si es, ó no, sucedaneo conveniente.

Dicha especie de Gatinsogea es muy comun en los contornos de Puebla, y otras partes de la Republica.

\section{Muerdago. (Vease Viscocuercino.)}

\section{Ombligo de Venus. (Cotiledon Umbilicus, $L$,)}

En lugar de esta planta se usan comunmente en las boticas, otras de generos muy distintos, siendo la mas frecuente una especie del genero Hydrocotyle, $\boldsymbol{L}$., cuya sustitucion debe omitirse, $y$ usar en su lugar el Sedum annurum, $\boldsymbol{I}_{\text {., }}$ conocido con el nombre yulgar de yerva de San Nicolas, por ser generos muy analogos el Cotyledon, Sedum y Sempervivum, que abundan en esta Republica. 


\section{Oregano. (Origanum Vulgare, L.)}

No obstante estar propagado en las huertas y jardines, $y$ de conocerlo y usarlo en las boticas, se gasta en ellas otro llamado Oreguno de Tehuacun (Lippia Origanoides, 员.), cuyo olor es semejante al del Oreg*ano Vulgar, aunque mas activo, y sus virtudes podran ser mas eficaces. Se nos trae de 'Tehuacan, en cuyos contornos es abundante.

NOTA. En las tiendas de Puebla se gasta otro Oregano, cuyo genero во ha podido averiguarse por no haberse conseguido la planta en disposicion de poderse verificar.

\section{Pareira brava. (Vease Buiua.)}

Pata de Leon. (Vease Alquimila.)

\section{Poligala.}

Entre las varias especies que hasta el dia se conocen, son tres las que principalmente se usan en la medicina, á saber: la Amarga (Polygala amara,) la comun (Polygala vulgaris) y la de Virginia [Polygala Senega] todas de L.; pero en la Republica se usa la Polygala tricosper. $m a, L$, que se da en los alrededores de México, cuya raiz, ya seca, es de un eolor que tira á gris, algunas nudosas, $y$ otras flexuosas; su 
sabor al principio insipido y mucilaginoso, y despues acre y picante; su olor alguu tanto aromatico cuando ha estado bien repuesta.

Por sus virtudes emeîca, purgante, diaforetica, diuretica y espectorante, conviene principalmente con la Polygala Senega, y por consiguiente es un sucedaneo apropiado de ella y de las otras especies.

\section{Polipodio. (Potypodium Vulgare, L.)}

Hasta ahora no se ha encontrado esta especie en la Republica, y se sustituye en su lugar la raiz del Polipodio de color de oro (Polypodium aureum, L.), que se cria en los montes proximos á Puebla. Como son de un mismo genero, es regular convengan tambien en sus virtudes, segun parece haberlo acreditado la esperiencia, y por lo mismo puede considerarse como un sucedaneo apropiado.

\section{Ruda Capraria. (Galega offieinalis, L.)}

Esta planta, cuyo zumo entra en la composicion del Agua triacal de Pedro de Salas, no se da en esta Republica, y en su lugar se gastan dos especies de Psoralea, abundantes en ella, que son la Psoralea Dalea, L., y Psoralea Citrodora, Cav, y pueden considerarse ventajosos estos sucedaneos, atendida la mayor actividad de su olor y sabor. 


\section{Salvia. (Salvia Officinalis, L.)}

Apenas se encontrarà un pais mas abundante de Salvias que esta Republica, y sin embargo aún no se ha hallado la oficinal, ni tampoco se usa por ella una especie de su genero, pues la que se gasta en algunas partes con el nombre de Salvia real, es la Budlea globosa, Lam., y en Puebla una especie de Lippia (Lippia umbellata, Cav. Lippia Callicarpaefolia, K.) que es una planta fruticosa, muy abundaute por Matamoros y sus contornos: su olor es mucho mas activo que el de la Salvia oficinal, y el sabor semejante al de esta, y por lo mismo deben esperarse efectos mas favorables de su uso, llenando con ventajas las indicaciones en que se aplica aquella, y siendo tambien superiores sus virtudes á las de la Budlea.

\section{Sinfito mayor ó Sueldaconsuelda. (Symphytum officinale, $L$,)}

Esta planta es enteramente diversa de la que se gasta en nuestras boticas por Sueldaconsuelda. Las virtudes que se le atribuyen á la raiz del Sinfito oficincl, son: mucilaginosa, vulneraria, y utilisima en la hemopthisis, diarrea, disenteria y ulceras de la Vejiga; y aplicada esteriormente consolida las fracturas de los hnesos, por lo que la llaman vulgarmente Suelda- 
consuelda. La Sueldaconsuelda que usamos nosatros son las raices de la Potentila multifida, y la Potentila aurea. L, muy comunes en la Republica, cuyas virtudes son astringentes, y pudieran sustituirse muy bien por la bistorta y tormeniila; no debiendo despreciarse el uso que se hace vulgarmente de dichas raices en polvo, mezclado con el de arrayan (Myrtus communis, L.), y trementina comun, para bizmas en la cadera y contusiones.

Como el Sinfito oficinal corresponde al orden natural de las asperifolias, pudiera sustituirse para uso interno con la borraja y su raiz (Borago officinalis. L.) que es abundante; y tambien esta por la Buglosa (Anchusa officinalis, L.), y por la Pulmonaria manchada (Pulmonaria officinalis, L.)

\section{Sucino. (Succinun electricum, $L$.)}

Se le da el nombre de sucino del pais, ò Cuapinoli, á la resina anime que produce la Hymenaea Courbaril, L.

Es una resina seca, blanquecina en la superficie, trasparente en lo interior, brillante en su fractura, de un sabor que se acerea al de la trementina y de olor agradable cuando se quema. Se ha solido usar en las boticas por el Sucino, cuya sustitucion es impropia, y por lo mismo debe abandonarse, destinandola solamente para el uso muy comun que en el dia tiene en la preparacion de los escelentes charoles. 
Nos viene generalmente por el comercia de Oajaca, en cuyo Estado se produce por los montes de la villa de Tecoantepec y pueblo de Petapa, y tambien en las cercanias de Chilpancingo y Chilapa.

\section{Sueldaconsuelda. (Vease Sinfito mayor)}

\section{Taray. (Thamarix Gallica, L.)}

Por el leño de este árbol se usa el de Ia Viborquia polystachya, Orteg., conocido vulgarmente con el nombre de palo dulce; y sus virtudes, segun parece de la observacion comun, son iguales à las del legítimo taray. Produce en corta cantidad una sustancia gomosa, que algunos suelen usar disuelta en agua para consumir las nuves de los ojos.

Crece cerca de Puebla y México.

\section{Tilo. (Tilia Europaea, L.)}

La flor de este árbol es de uso muy comun en las boticas; pero en las nuestras, con muchas ventajas y á menos costo, la flor del tilo del pais (Tilia americana, L.)

Es árbol propio de la República, y su for la llevan los indigenas á México, en cuyo jardin botánico hay un individuo del mismo género $\mathrm{y}$ especie. 
Torongil. (Melissa Officinalis, L.)

Por esta planta se gasta en la República la Nepeía Citrodora, F. M. I. Es muy aromática, y sobresale en ella el olor de cidra, de donde se le diò el nombre específico trivial. Sus virtudes son seguramente superiores á las del torongit, por escederle mucho en olor y sabor; $y$ su aceite volatil, que es de un olor agradable, tiene bastante estimacion dentro $y$ fuera de la Redública.

Se cultiva en los jardines, huertas y chinampas (1) de Ixtacalco y Xochimilco. En los montes se da una variedad de esta especie con olor de poleo, (Mentha pulegium, L.), que podria sustituirse por él.

\section{Verbena. (Verbena Officinalis, L.)}

Aunque no falta esta especie en la República, es mucho mas abundante la Verbena carolineana, L., y esta es la que se gasta comunmente en las boticas de Puebla; y siendo muy semejantes en su olor $y$ sabor, deben serlo tambien en las virtudes, y por consiguiente está bien fundada la sustitucion.

(1) Huertas flotantes en la laguna de México [donde se cultivan flores y hortalizas que se consumen en aquella Ciudad], y en caso de necesidad se conducen con facilidad a remolque de un punto de la laguna a otro. 


\section{5}

\section{Viscocuercino ó muérdago. (Viscum.Album,L.)}

En lugar de esta planta se usa generalmente en nuestras boticas el Loranthus americanus, L. que es algo semejante al Viscocuercino, y sus propiedades parece son las mismas. Nace sobre los árboles, y es muy comun en los contornos de Puebla.

\section{Yedra terrestre. (Glecoma Hederacea, L.)}

Tres plantas suelen sustituirse por esta, que son: el sombrerillo de agud de américa (Hydrocotile americana, L.), que se cria en Jalapa, y sus hojas son tan parecidas á las de la yedra terrestre que pudieran equivocarse con ellas, y por lo mismo conviene que se tenga esta noticia para no confundir una planta con otra por ser de virtudes muy diferentes La campanilla ó manto de la virgen (Ipomea violacea, L.), euya sustitucion debe considerarse impropia por corresponder esta planta á una familia, cuyas especies son mas ô menos purgantes. Y la Covaea Scandens, Cav, de ta que aun no se tienén observadas sus virtudes.

Por las razones espuestas se echará de ver que de ningnn modo conviene usar las referidas plantas por la yedra terrestre, y si tratar de su propagacion que debe ser fácil, como se observa en Pnebla, en donde se cultiva en algunas huertas; usando entre tanto la estrangera. 
Yerba de la golondĩna. (Vease Celidonia,

\section{Vezgos. (Sambucus Ebulus, L.)}

Por la raiz de esta planta está generalmente estendido el uso de la que produce una especie de Ortiga (Urtica mexicana, F. M. I.), y la aplican como sudorifica y antivenerea, con efectos favorables, segun la observacion de varios facultativos, por lo que puede considerarse como un verdadero sucedaneo del yezgo.

Crece por todas partes.

Su raiz es cundidora de cinco ò mas pies de larga, cuyo grueso en las antiguas llega al del dedo pulgar, con articulaciones aproximadas, compuestas de una sustancia fibrosa esponjosa, interiormente blancas, y cubiertas en lo esterior de una corteza de color amarillo que tira á rojo: las mas tiernas, del grueso del dedo meñique, con articulaciones mas distantes, color rojo claro esteriormente, y de la misma sustancia que las antiguas. Echa el tallo herbaceo, derecho, sencillo, de tres ấ cuatro pies de altura, con articulaciones, asurcado y picante. Las hojas, opuestas, entre aovadas y oblongas, ogudas, aserradas, nerviosas, con la superficie áspera y rugosa, blanquecinas en el envés y algo pelosas. Los pezones, muy cortos, acanalados y con algunos pelos. Estipulas, entre lineares y lanceoladas, agudas, concavas por la parte esterior y revueltas por 


\section{7}

la punta. Las flores masculinas se hallan co. locadas en espigas verticiladas, que nacen de 4 en 4, divididas en espiguillas de muchas flores, y mas cortas que las hojas. Las flores femeninas estan situadas en la parte superior del tallo y sobre las masculinas, siendo su inflorescencia igual á la de estas.

\section{OBSERVACION.}

La situacion de las fores femeninas es muy variada en esta especie: unas veces - so encuentran solas en un pie de planta, otras simultaneamęnte debajo y encima de las masculinas, y otras, que suele ser lo mas frecuente, solo sobre estas mismas,

Se encuentran en esta especie algunos caractères que la aproximan á la Urtica Stalonifera, Sw.

\section{Zumaque. (Rhus Coriaria, L.)}

Esta especie es la que se cultiva y gasta en Europa para adobar las pieles en las tenerias. Es tambien la que se usa en aquellas boticas; pero en las de Puebla es otra especie llamada Zumaque del paìs [Rhus mollis, K.], que aunque es menos astringente, puede considerarse como un sucedaneo apropiado. 


\section{COPI}

de algunos párrafos del discurso del botánico Don Mariano Nocin̄o, citado en el pròlogo de este Ensayo, que espresan varias producciones medicinales de la Repùblica, de las que se hacia uso en las salas de observaciones establecidas en los hospitales generales de la capital de México, á principios del presente siglo. "Asi es, dice, que para las indicaciones de los astringentes usamos las raices de las Kramerias, de las Alchemillas, y de las Potentilas, y para el uso esterno el jugo de la Tezcalama (Ficus nymhipaeifolia), el del ule [Castilloa elastica], y para el intérno y esterno el zumo de agraz, y dos especies de sangre de drago, que son el verdaderamente tal, (Pterorocarpus draco), y el Eztquahuitl [Croton Sanguiferum]. Nuestros emolientes son todas las columníferas: nuestros Corrosivos son el Tlepatli (Plumbago lanceolata), la corteza de la semilla del Marañon [Anacardium occidentale], la del tronco de la Daphne laureola, los ajos, y todos los chites. Las cataplasmas de la mostaza son el epispastico de que usamos con mas frecnencia y con mas felicidad."

"Las raices del Gengibre, del Costus spicatus y la Maranta galanga, son escelentes estimulantes aromáticos, $\mathrm{y}$ en el òrden de los frograntes apenas habrá cosa mejor que el Romero, la Monarda pestañosa, la Yoloxockill 


\section{9}

(Magnolia glauea), el Topozan [Budleia occidentalis], y muchas especies de Salvias muy olorosas, á mas de innumerables del òrden natural de las verticiladas. Las Peperomias y la Yerba Santa [Piper Sanctum], nos sirven en el caso que necesitamos picantes suaves, y si queremos medicinas acres las hallamos en el Tzacutlaxcali [Cuscuta americana], en la Coanabiichi (Hypocratea voluvilis), la corteza del Drimis Winteri, y las semillas de la Algalia (Hibiscus abelmoscus)"

"Tenemos entre las narcoticas la cabeza de la Adormidera, las hojas de la Ciouta [Conium maculatnm], la Yerba mora (Solanum nigrum), el Toloache [Datura Stramonium], y el Tabaco."

"Nuestros refrigerantes, diluentes y atemperantes son, ó el agua sola, ò mezclada con algunos acidos, como el Tamarindo, la piña [Bromelia ananas] y los Tumbirichis [Bromelia Pinguin], las sales neutras, los jabones, la Miel y el Azucar son nuestros atenuantes, y nuestros demulcentes la semillas. llamadas vulgarmente frias mayores, la cebada, la Lippia dulce, el Nanahuapatli [Smilax aspera], y el cololmecatl [Smilax china]," Smitax rotundifolia $L$.

"Nuestros febrifugos, tomicos y anlisepticos son las raices de las Barbudillas [Dorstenia contrayerra. Drakenia Housoni], el palo del Quasi [Quasia amara] el copatchi de Gradalajara (Portlandia hexandria) el de Tehuantepeque [Croton febrifugum], el de Costa rica [Croton 


\section{0}

Cascarilla], la Prodigosa [Athanasia amara], el haba de San Ignacio contrayerba de Julimes (Asclepias ba)."

"La raiz del galo (Valeriana Phú), el $\boldsymbol{c} a$ caloxochitl. [Plumeria alba], el Fepazoll [chenopodium ambrosioides], el Eneldo, el Hinojo, el Anis y la muda, son los antiespasmodicos vegetales de nuestro uso, á que agregamos el hollin, las sales allialinas volatiles, los aceyles èsenciales y empyreumaticos, como tambien los Espiritus etereos. Nuestros Errhinos son la raiz del Lirio morado. y las hojas de la Nama errhina. Nuestros Sialagogos el T'abaco y las peperomias: el mismo Tabaco nos sirve de expectorante, como tambien el Pancralio ilirico."

"Usamos poquísimas veces de los eméticos y purgantes, porque son tambien poquísimas las ocasiones en que nos parecen estar verdaderamente indicados, $y$ en estos casos hacemos vomitar con nuestra Viala verícilada ó con la Poligala tricosperma, ó con el Estropajo de Qajaca (Luffa fricatoria), y purgamos con el Sulfuto de sosa ò con la Yerba del Zorrillo [Croton vulpinum]; contando, para cuando la indicacion lo exija, con la Cañafistola, con el Blechoacan, la Jalapa, y otros muchísimos catarticos de que abunda nuestro territorio, sin necesidad del consumir una sola ochava de maná" "Todas las plantas llamadas comunmente diureticas, son nuestras, o por lo menos la mayor parte de ellas, y entre las diuforèticas 


\section{1}

tenemos el Guayacan y al Sasafras que, esceptuando el opio y el Almizcle, valen por el ma yor nùmero de las medicinas de esta clase. Para menagogos contamos con la Valericina Phù, la Iris Sambucina, el Eringio fetido, el comino, el culantro, y el balsamo de Guatemala."

\section{ERRATAS.}

En la pàgina IV. línea 9 dice, $\mathrm{cl}$ autor

Lease el autor.

En la página V. línea 28 dice, repocision.

Lease reposicion.

En là pàgina V1II. lìnea 29 dice, respectables.

Lease respetables.

En la pigina 8 línea 18 dice, virtndes.

Lease virtudes.

En la pàgina 17 línea 4 dice, la hojas.

Lease las hojas,

En la página 17 línea 6 dice, mncho.

Lease mucho.

En la pàgina 21 línea 17 dice, Capuli, Cav.

Lease Salicifolia, $K$.

En la pàgina 31 lìnea 24 dice, Pepitas de Sopilote.

Lease Pepitas de Zopilotl.

En la página 41 linea 9 dice, lo República.

Lease la Repiblica.

En la página 41 lìnea 22 dice, porticularidad.

Lease particularidad.

En la página 46 línea 21 dice, aprecio.

Lease $d$ precio.

En la página 52 línea 16 dice, Scnecio.

Lease Senecio.

En la página 61 línea 12 dice, Bczoardico.

Lease Bezoardico.

En la página 64 linea 11 dice, Cactus Opnntia.

Lease Cactus Opuntia.

En la página 70 línea 30 dice, Ahrchipin.

Lease Archipin

En la página 71 línea 6 dice, Junguillo ó yerba ae.

Lease Junquillo d yerba de.

En la página 95 línea 28 dice, Puebla.

Lease Prebla. 